\title{
Development of novel 2D and 3D correlative microscopy to characterise the composition and multiscale structure of suspended sediment aggregates.
}

Article in Continental Shelf Research · April 2020

DOI: $10.1016 /$ j.csr.2020.104112

CITATIONS

0

5 authors, including:

Jonathan Wheatland

Queen Mary, University of London

9 PUBLICATIONS 5 CITATIONS

SEE PROFILE

Ian G. Droppo

Environment and Climate Change Canada

160 PUBLICATIONS 4,270 CITATIONS

SEE PROFILE

Some of the authors of this publication are also working on these related projects:

Defining functional microbial characteristics in natural systems View project

Oil Sands Reclamation and microbial function View project
READS

Kate L Spence

Queen Mary, University of London

61 PUBLICATIONS 943 CITATIONS

SEE PROFILE

Simon James Carr

University of Cumbria

64 PUBLICATIONS 1,012 CITATIONS

SEE PROFILE 


\section{Journal Pre-proof}

Development of novel 2D and 3D correlative microscopy to characterise the composition and multiscale structure of suspended sediment aggregates.

Jonathan A.T. Wheatland, Kate L. Spencer, Ian G. Droppo, Simon J. Carr, Andrew J. Bushby

PII: S0278-4343(20)30068-6

DOI: https://doi.org/10.1016/j.csr.2020.104112

Reference: CSR 104112

To appear in: Continental Shelf Research

Received Date: 5 August 2019

Revised Date: 20 March 2020

Accepted Date: 30 March 2020

Please cite this article as: Wheatland, J.A.T., Spencer, K.L., Droppo, I.G., Carr, S.J., Bushby, A.J., Development of novel 2D and 3D correlative microscopy to characterise the composition and multiscale structure of suspended sediment aggregates., Continental Shelf Research (2020), doi: https:// doi.org/10.1016/j.csr.2020.104112.

This is a PDF file of an article that has undergone enhancements after acceptance, such as the addition of a cover page and metadata, and formatting for readability, but it is not yet the definitive version of record. This version will undergo additional copyediting, typesetting and review before it is published in its final form, but we are providing this version to give early visibility of the article. Please note that, during the production process, errors may be discovered which could affect the content, and all legal disclaimers that apply to the journal pertain.

(C) 2020 Published by Elsevier Ltd. 


\section{Journal Pre-proof}

1 Development of novel 2D and 3D correlative microscopy to characterise the composition and multiscale structure of suspended sediment aggregates.

4 Jonathan A.T. Wheatland $^{\text {a,b,c }}$, Kate L. Spencer ${ }^{c}$, Ian G. Droppo ${ }^{\text {d }}$, Simon J. Carr ${ }^{\text {c,e }}$

$5 \quad$ Andrew J. Bushby ${ }^{a, b, *}$

6 a School of Engineering \& Materials Science, Queen Mary University of London, Mile

7 End Road, London E1 4NS, UK

$8{ }^{\mathrm{b}}$ The NanoVision Centre, Queen Mary University of London, Mile End Road, London

$9 \quad$ E1 4NS, UK

$10{ }^{\mathrm{c}}$ School of Geography, Queen Mary University of London, Mile End Road, London

11 E1 4NS, UK

$12{ }^{d}$ Environment and Climate Change Canada, 867 Lakehouse Road, P.O. Box 5050,

13 Burlington, Ontario L7S 1A1, Canada

14 e Department of Science, Natural Resources and Outdoor Studies, University of

15 Cumbria, Ambleside, Cumbria LA22 8BB, UK

16 * Corresponding author. Email address: a.j.bushby@qmul.ac.uk

Abstract

19 Suspended cohesive sediments form aggregates or 'flocs' and are often closely

20 associated with carbon, nutrients, pathogens and pollutants, which makes

21 understanding their composition, transport and fate highly desirable. Accurate

22 prediction of floc behaviour requires the quantification of 3-dimensional (3D) properties (size, shape and internal structure) that span several scales (i.e. nanometre $[\mathrm{nm}]$ to millimetre [mm]-scale). Traditional techniques (optical cameras and electron microscopy [EM]), however, can only provide 2-dimensional (2D) 
simplifications of 3D floc geometries. Additionally, the existence of a resolution gap between conventional optical microscopy (COM) and transmission EM (TEM) prevents an understanding of how floc nm-scale constituents and internal structure influence mm-scale floc properties. Here, we develop a novel correlative imaging workflow combining 3D X-ray micro-computed tomography $(\mu \mathrm{CT})$, 3D focused ion beam nanotomography (FIB-nt) and 2D scanning EM (SEM) and TEM (STEM) which allows us to stabilise, visualise and quantify the composition and multi-scale structure of sediment flocs for the first time. This new technique allowed the quantification of 3D floc geometries, the identification of individual floc components (e.g., clays, non-clay minerals and bacteria), and characterisation of particle-particle and structural associations across scales. This novel dataset demonstrates the truly complex structure of natural flocs at multiple scales. The integration of multi scale, state-of-the-art instrumentation/techniques offers the potential to generate fundamental new understanding of floc composition, structure and behaviour.

\section{Keywords}

Aquatic sediments, sediment aggregates, flocs, multiscale imaging, 2D and 3D correlative microscopy

\section{Introduction}

Cohesive fine-grained sediments and mixed sediments in suspension influence a wide array of environmental processes and material transfers, including the transport, fate and effect of carbon, nutrients, microbiota (including pathogens) and pollutants within lakes, rivers, estuaries and the marine environment (Azam \& Long 2001; Rusconi et al. 2014; Rummel et al. 2017). Understanding the composition and behaviour of cohesive and mixed sediments is therefore a major issue for the 
management of aquatic environments. However, in suspension this biotic and abiotic particulate matter forms loosely bound, complex and fragile aggregates, or 'flocs'.

Flocs exhibit hydrodynamics (e.g., transport dynamics and settling) that differ

significantly from those of their constituent particles (Droppo 2001; Burd \& Jackson 2009; Manning et al. 2010).

To predict the movement of cohesive sediments requires accurate

quantification of floc properties that control their behaviour (e.g., size, shape, porosity and density) (Soulsby et al. 2013). Additionally, an understanding of floc composition and particle associations provides a mechanistic understanding of e.g., pathogen and pollutant transport and elucidates microbial dynamics (Liss 2002). Yet, obtaining such empirical data is challenging since flocs are inherently fragile and their properties often span several spatial scales, i.e. $\mathrm{nm}$ to $\mathrm{mm}$-scale. Flocs are routinely characterised based on their 'gross' scale properties (e.g., external size and shape) that can be measured in situ relatively simply and non-destructively. Floc camera systems (e.g., LabSFLOC, Manning \& Dyer 2002) and laser diffraction particle sizers (e.g., LISST, Agrawal \& Pottsmith 2000) are commonly used and provide additional measurements of floc settling velocities. Internal floc characteristics (e.g., structure, density and porosity) cannot be measured directly using these methods, but can be estimated using Stokes' Law and the assumption of spherical shape and fractal behaviour, i.e. structural self-similarity (Winterwerp 1998; Jarvis et al. 2005). Alternatively, sub- $\mu \mathrm{m}$ structures and the internal composition can be observed by, for instance, TEM (Leppard et al. 1996) or optical measurement of cell colonisation (e.g., Nguyen et al. 2017). However, there is no one method that allows floc structure and composition to be observed at all relevant spatial scales or that reflects the inherent 3D nature of these characteristics. A major challenge 
therefore is the development of methods that enable empirical observation and accurate quantification of floc characteristics, correlated across multiple lengthscales.

The combined application of two or more imaging methods, known as correlative microscopy, overcomes the resolution limitations associated with using a single imaging technique (Liss et al. 1996; Burnett et al. 2014). Previously, COM has been applied correlatively with confocal laser scanning microscopy (CLSM) and TEM enabling the investigation of floc mm-and nm-scale properties (Leppard 1992;

Droppo et al. 1996; Liss et al. 1996; Leppard et al. 1996). Observations using this approach have provided valuable insights into floc structure-function relationships, highlighting the importance of floc-colonising microorganisms and their associated exopolymeric substances (EPS) (Droppo 2001; Tolhurst et al. 2002). However, the use of these imaging methods in a truly correlative manner is hindered by the specific preparation requirements, differences in contrast mechanisms, lack of overlap in resolution and their 2-dimensionality. Methods that can combine different spatial scales and similar contrast mechanisms with both 2D and 3D information are needed to understand delicate floc structures that include both organic and inorganic materials that extend across multiple scales. The combination of X-ray tomography with EM has the capability to achieve this across length-scales from $\mathrm{mm}$ to $\mathrm{nm}$ and the resolution gap can be closed. Furthermore, with similar sample preparation procedures, both imaging techniques can be applied to a single floc sample. Such methods have been used within materials science to visualise and quantify complex, multiscale structures from the $\mathrm{cm}$ to $\mathrm{nm}$-scale (Handschuh et al. 2013; Burnett et al. 2014), and in the biological sciences (Bushby et al. 2012), but have not yet been applied to study natural environmental samples. 
$\mu \mathrm{CT}$ and FIB-nt are both capable of imaging complex samples in 3D. $\mu \mathrm{CT}$ is

102 segment the datasets. behaviour.

capable of analysing volumes at a higher resolution than COM, and for small samples can reach a resolution of tens of $\mu \mathrm{m}$ down to submicrometre (Cnudde \& Boone 2013). It is non-destructive and thus suited to imaging delicate samples, including sediments and hydrated, flocculated clays (e.g., Sharma et al. 2017; Zhang et al. 2018). FIB-nt is capable of resolutions approaching that of TEM (c. $10 \mathrm{~nm}$, Holzer et al. 2004), and occupies a niche between TEM and $\mu \mathrm{CT}$. Although FIB-nt is destructive, delicate samples can be stabilised to preserve their integrity during analysis (e.g., Bushby et al. 2011), and it has recently been successfully applied to investigate the internal structure of hydrated flocs (Wheatland et al. 2017).

Significantly, both $\mu \mathrm{CT}$ and FIB-nt provide quantitative data (Holzer et al. 2004;

Ketcham \& Carlson 2001), which can be used to characterise suspended sediment flocs and potentially parameterise computational models that describe floc

The aim of this study is to develop a correlative workflow that enables observation, characterisation and quantification of natural suspended sediment floc structure and composition from the $\mathrm{mm}$ to $\mathrm{nm}$-scale for the first time. This workflow, which combines 3D $\mu \mathrm{CT}$ and FIB-nt with 2D SEM and STEM, is applied to the investigation of natural estuarine sediment flocs. Based on feature greyscale, size and morphology criteria are developed to distinguish floc components (e.g., clay minerals, bacteria etc.) observed at different spatial scales, which are used to 
124 2. Materials and Methods

\section{2.1. Considerations for Correlative Imaging}

126 Several challenges exist for the correlative imaging of sediment flocs. Firstly, fragile

127 flocs must be sampled and stabilised and contrast agents (e.g., stains) applied to

128 enable feature recognition using different imaging modalities operating at different

129 scales (Wheatland et al. 2017). MCT and EM share similar contrast mechanisms

130 allowing object(s) of interest to be identified and correlated between datasets.

131 However, electron-dense stains must be introduced to allow organics to be

132 distinguished. Secondly, to achieve correlation between the different imaging

133 methods, datasets must be registered using fiducial markers that can be imaged by

134 all methods. Thirdly, the process of identifying $\mathrm{nm}$-scale datasets nested within $\mathrm{mm}$ -

135 scale samples is represents a significant challenge (Bushby et al. 2011; Burnett et al.

136 2014). Therefore, workflows must follow a targeted approach whereby a sample is

137 sequentially imaged at a finer scale and/or by a complimentary modality, the data

138 from which is used to selected further regions of interest (Rol) for analysis at higher

139 resolutions. Finally, the imaging methods used should each adequately resolve both

140 the biotic and abiotic floc components for correlation. For example, $\mu \mathrm{CT}$ maps X-ray

141 attenuation and hence images the density of an object or concentration of floc

142 constituents at the $\mu \mathrm{m}$ to $\mathrm{mm}$-scale. In comparison, SEM (using secondary and

143 backscattered electrons) provides information on morphology and elemental

144 composition at the $\mathrm{nm}$ to $\mu \mathrm{m}$-scale. Combining this information enables important

145 features (e.g., a pore space, clay mineral or bacteria) to be identified at different

146 scales and resolutions. Once features have been identified, they can be segmented,

147 quantified and visualised in both $\mu \mathrm{CT}$ and FIB-nt. 


\subsection{Floc Capture and Stabilisation}

150 Natural sediment collected from the Thames Estuary, SE England. These sediments

151 are typically fully saline, fine grained silty clays with organic content typically $<10 \%$

152 (measured as \% loss on ignition, e.g., O'Shea et al. 2018). Sediment was added to

153 an artificial seawater solution (Sigma sea salts $34 \mathrm{~g} \mathrm{~L}^{-1}$ ) and gently agitated using a

154 magnetic stirrer to induce flocculation. Fragile flocs were sampled following the

155 protocol outlined in Droppo et al. (1996), which involved settling flocs directly into

156 plankton chambers and immobilising flocs in agarose gel. $\mu$ CT scans of a test

157 sample (FS0, see Fig. S1 of Supplementary Materials) were conducted in order to

158 assess potential artefacts associated with this technique (e.g., particle-particle

159 overlap, Droppo et al. 1996). Immobilised flocs were subsequently prepared for

160 imaging following the block staining protocol outlined in Wheatland et al. (2017). Floc

161 samples were rendered vacuum stable by resin embedding, which included the

162 addition of electron dense stains (e.g., uranyl acetate etc.) to improve the contrast of

163 organic constituents. Following resin embedding, fiducial markers (aluminium wire, c.

$1640.5 \mathrm{~mm}$ diameter) were implanted in the base of each resin block for the purpose of 165 data co-registration (see Section 2.3). Aluminium was selected as it could be easily

166 distinguished from natural sedimentary material using all imaging methods

167 (Handschuh et al. 2013). 


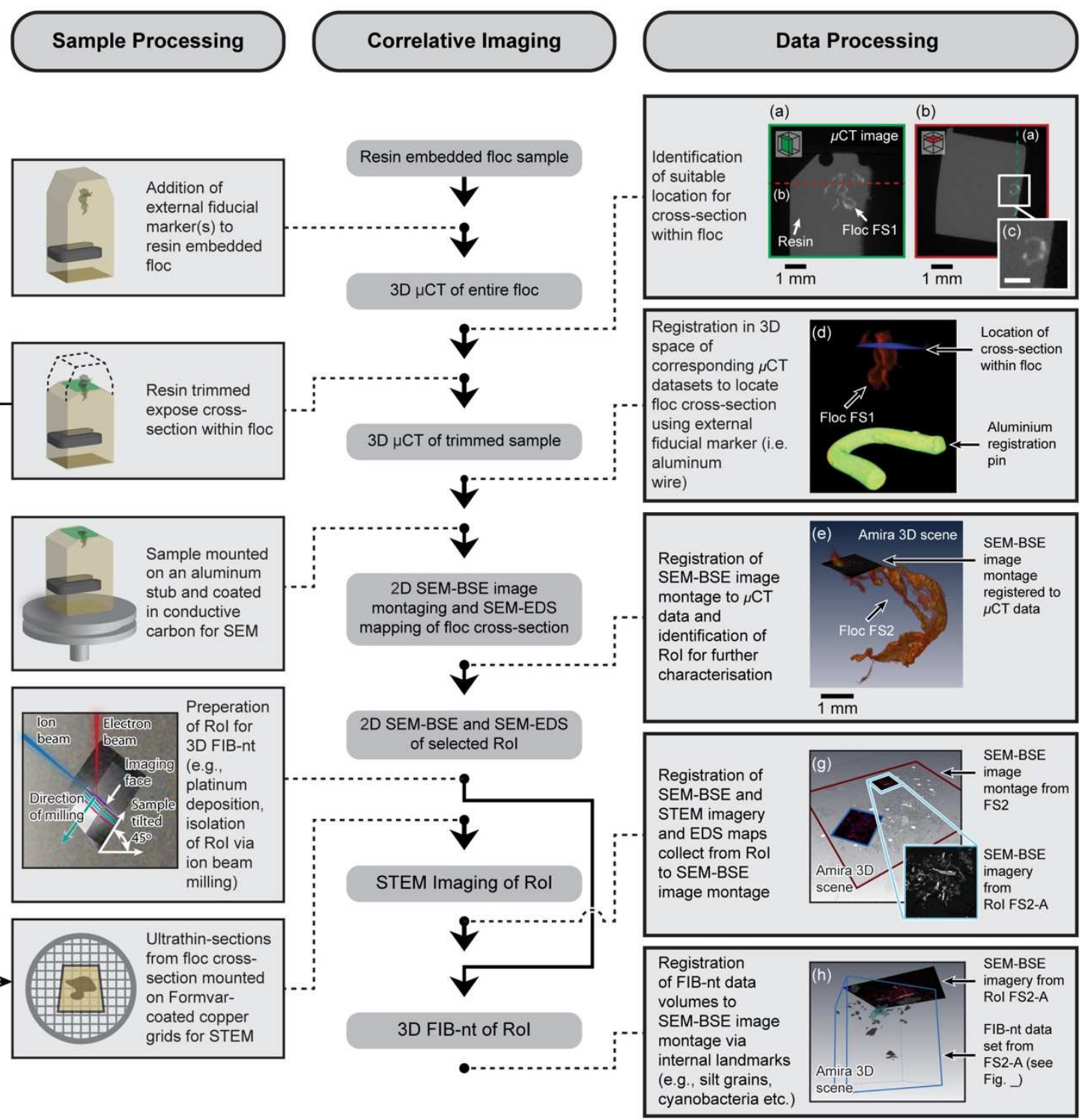

Figure 1. Flow diagram outlining the various stages in the correlative imaging workflow, including steps required for sample and data processing. Images (a) and (b) are orthogonal slices from the $\mu \mathrm{CT}$ scan of floc FS1. Grey-scale variations reflect regions of high and low X-ray attenuation (c), and indicate variability of floc constituents and structure at the sub-voxel scale. This information helps guide the selection of a suitable site for a cross-section within the floc which is exposed via ultramicrotomy. The precise location of the cross-section within the floc is then verified by re-scanning the sample using $\mu \mathrm{CT}$ and registering the two corresponding $\mu \mathrm{CT}$ datasets using the aluminium registration pin (d). 2D SEM-BSE image montages of the floc cross-section, obtained to identify suitable Rol for further analysis, are then registered to the $\mu C T$ data (e). Following 2D SEM-BSE imaging, Rol are prepared for 3D FIB-nt (h). 2D SEM-BSE and STEM imagery and 3D FIB-nt data obtained from Rol can be registered to the image montage based on 'internal' fiducial markers (e.g., silt grains, cyanobacteria etc.) that can be identified in the corresponding datasets ( $g$ and $h$ ). 


\subsection{Description of the Correlative Workflow}

171 The correlative workflow developed for investigating floc composition and multiscale

172 structure is shown in Fig. 1. Low-resolution $\mu \mathrm{CT}$ scans (3D pixel or 'voxel' size, c. 10

$173 \mu \mathrm{m}^{3}$ ) were initially conducted to characterise floc size and morphology and identify

174 Rol for further analysis (Fig. 1a and b). At this resolution individual floc constituents

$175<100 \mu \mathrm{m}$ (e.g., bacteria and clay minerals) cannot be resolved. However, variations in X-ray attenuation (Fig. 1c and Fig. S2 of Supplementary Materials) indicate the variability of floc constituents and structure at the sub-voxel scale. Subsequently, selected Rols were exposed by trimming the resin-block using an ultramicrotome (Leica UCT ultramicrotome), creating a smooth cross-section suitable for 2D SEM and 3D FIB-nt. During this process, ultrathin-sections (thickness, 70-100 nm) cut directly adjacent to the cross-section were retained for STEM (Fig. 1).

The accurate co-registration of $\mu \mathrm{m}$ and $\mathrm{nm}$-scale EM datasets with mm-scale $\mu \mathrm{CT}$ scans relied on the location and characterisation of the cross-section created within the floc. Therefore, samples were re-scanned using $\mu \mathrm{CT}$ following ultramicrotomy to locate the floc cross-section within the original $\mu \mathrm{CT}$ data (Fig. 1d).

186 This was facilitated by 'external' fiducial markers (aluminium wire) identifiable in the corresponding $\mu \mathrm{CT}$ datasets (Fig. 1d, see section 3.1.1). To ensure these repeat scans were directly comparable to the original $\mu \mathrm{CT}$ data and accurate coregistration, the position of the mechanical stage, manipulator settings (i.e. voltage and current) and resolution were kept constant. 2D SEM-BSE image montaging of the cross-section (block-face SEM) then provided the context within which to locate 3D FIB-nt volumes and 2D STEM imagery based on identification of 'internal' landmarks within the floc (Fig. $1 \mathrm{~g}$ and $\mathrm{h}$ ).

194 Landmarks were selected that could be identified across scales and imaging 
195 modalities, e.g., silt grains and cyanobacteria (see Table 1). Image montages were

196 obtained by systematic imaging using 2D SEM, resulting in 10's - 100's of images

197 that were stitched together to provide a 'panoramic' view of the entire cross-section

198 (pixel resolution, c. $100 \mathrm{~nm}^{2}$ ). Following SEM imaging, elemental maps were

199 obtained from selected Rol via energy dispersive X-ray spectroscopy (SEM-EDS)

200 which, in conjunction with contrast and morphological information from SEM

201 imagery, enabled identification and mapping of materials.

202 2D SEM imagery and EDS maps informed the selection suitable sites for 3D

203 FIB-nt. Representativity is a key consideration when selecting parameters for FIB-nt

204 (i.e. volume size and resolution), and must be optimised to resolve features of

205 interest and ensure that a representative number of particles are characterised for statistical analysis (Bushby et al. 2011). Natural flocs are compositionally complex, containing particles of varying morphology and size (e.g., blocky silt grains, platy clays, and filamentous organics), and high-resolution datasets are desirable (10-15 $\mathrm{nm}$ ) to characterise individual particles. However, a trade-off must be made between

210 the resolution and volume size to ensure the $\mu \mathrm{m}$-scale structures into which floc

211 constituents are organised are adequately characterised.

\begin{tabular}{|c|c|c|c|c|c|c|c|}
\hline \multicolumn{8}{|c|}{ Imaging Technique; Successive Techniques Applied $\longrightarrow$} \\
\hline \multicolumn{2}{|c|}{ CT Datasets } & \multicolumn{2}{|c|}{ SEM-BSE Montaging } & \multicolumn{2}{|c|}{ SEM and STEM } & \multicolumn{2}{|l|}{ FIB-nt } \\
\hline Material & $\begin{array}{l}\text { Identification } \\
\text { Criteria }\end{array}$ & Material & $\begin{array}{l}\text { Identification } \\
\text { Criteria }\end{array}$ & Material & $\begin{array}{l}\text { Identification } \\
\text { Criteria }\end{array}$ & Material & $\begin{array}{l}\text { Identification } \\
\text { Criteria }\end{array}$ \\
\hline \multirow[t]{2}{*}{ Floc } & $\begin{array}{l}\text { Mid-range } \\
\text { greyscale (c. } \\
19,000- \\
40,000)\end{array}$ & \multirow[t]{2}{*}{$\begin{array}{l}\text { Floc } \\
\text { Matrix }\end{array}$} & $\begin{array}{l}\text { Material with } \\
\text { diameter c. } \\
<10 \mu \mathrm{m} \text {, low to } \\
\text { mid-range } \\
\text { greyscales (c. } \\
20-200 \text { ) }\end{array}$ & $\begin{array}{l}\text { Clay } \\
\text { Minerals }\end{array}$ & $\begin{array}{l}\text { 2D planar } \\
\text { morphology, } \\
\text { size c. }<5 \mu \mathrm{m} \text {, } \\
\text { mid-range } \\
\text { greyscale (c. } \\
10-170 \text { ) }\end{array}$ & $\begin{array}{l}\text { Clay } \\
\text { minerals }\end{array}$ & $\begin{array}{l}\text { 3D planar } \\
\text { morphology, } \\
\text { size c. }<5 \mu \mathrm{m} \text {, } \\
\text { mid-range } \\
\text { greyscale (c. } \\
10-170)\end{array}$ \\
\hline & $\begin{array}{l}\text { composition } \\
\text { and structure } \\
\text { at the sub- } \\
\text { voxel scale }\end{array}$ & & $\begin{array}{l}\text { Regions of low } \\
\text { and high } \\
\text { occupation }\end{array}$ & $\begin{array}{l}\text { Microbial } \\
\text { Cells }\end{array}$ & $\begin{array}{l}\text { Small size (c. } \\
<10 \mu \mathrm{m}) \text {, high } \\
\text { greyscale (c. } \\
200-250) \text {, }\end{array}$ & $\begin{array}{l}\text { Cell } \\
\text { Morpho- } \\
\text { type }\end{array}$ & $\begin{array}{l}\text { Five cell } \\
\text { morphotypes } \\
\text { recognised } \\
\text { based on } \\
\end{array}$ \\
\hline
\end{tabular}




$\begin{array}{ll}\begin{array}{l}\text { recognised } \\ \text { based on X-ray } \\ \text { attenuation: }\end{array} & \begin{array}{l}\text { identified } \\ \text { based on } \\ \text { greyscale, }\end{array} \\ \text { low greyscale } & \text { e.g., low } \\ \text { values (c. } & \text { occupation c. } \\ 25,000- & \text { occupation c. } \\ 40,000) & >70 \\ \text { correlated to } & \\ \text { regions of low- } & \\ \text { occupation, } & \\ \text { high greyscale } & \\ \text { values (c. } & \\ \text { 19,000 - } & \\ 25,000) & \\ \text { correlated to } & \\ \text { regions of } & \\ \text { high- } & \\ \text { occupation } & \end{array}$

\begin{tabular}{|c|c|c|c|}
\hline & \multicolumn{2}{|l|}{$\begin{array}{l}\text { differential } \\
\text { staining of } \\
\text { subcellular } \\
\text { structures }\end{array}$} & $\begin{array}{l}\text { criteria } \\
\text { outlined in } \\
\text { Dazzo \& } \\
\text { Niccum (2015) } \\
\text { (see Fig. 5) }\end{array}$ \\
\hline & & $\begin{array}{l}\text { Intra- } \\
\text { cellular } \\
\text { Integrity }\end{array}$ & $\begin{array}{l}\text { Three } \\
\text { categories of } \\
\text { intracellular } \\
\text { integrity } \\
\text { (indicative of } \\
\text { metabolic } \\
\text { state) } \\
\text { recognised } \\
\text { based on } \\
\text { criteria } \\
\text { outlined by } \\
\text { Heissenberger } \\
\text { et al. (1996) } \\
\text { (see Fig. 5) }\end{array}$ \\
\hline $\begin{array}{l}\text { Organo- } \\
\text { Mineral } \\
\text { Debris }\end{array}$ & $\begin{array}{l}\text { Geometric } \\
\text { structure, mid- } \\
\text { range } \\
\text { greyscale (c. } \\
10-170 \text { ) }\end{array}$ & $\begin{array}{l}\text { Organo- } \\
\text { Mineral } \\
\text { Debris }\end{array}$ & $\begin{array}{l}\text { Geometric } \\
\text { structure, mid- } \\
\text { range } \\
\text { greyscale (c. } \\
10-170 \text { ) }\end{array}$ \\
\hline
\end{tabular}

EPS material, diameter (2 -

NA $15 \mathrm{~nm})$

\begin{tabular}{|c|c|c|c|c|c|}
\hline $\begin{array}{l}\text { Non-Clay } \\
\text { Minerals }\end{array}$ & $\begin{array}{l}\text { Blocky/ } \\
\text { irregular } \\
\text { morphology, } \\
\text { particle size c. } \\
5-40 \mu \mathrm{m}, \\
\text { mid-range } \\
\text { greyscales (c. } \\
20-100)\end{array}$ & $\begin{array}{l}\text { Non-Clay } \\
\text { Minerals }\end{array}$ & $\begin{array}{l}\text { Blocky/ } \\
\text { irregular } \\
\text { morphology } \\
\text { Particle size c. } \\
5-40 \mu \mathrm{m}, \\
\text { mid-range } \\
\text { greyscales (c. } \\
20-100)\end{array}$ & $\begin{array}{l}\text { Non-Clay } \\
\text { Minerals }\end{array}$ & $\begin{array}{l}\text { Blocky/ } \\
\text { irregular } \\
\text { morphology } \\
\text { Particle size c. } \\
5-40 \mu \mathrm{m}, \\
\text { mid-range } \\
\text { greyscales (c. } \\
20-100)\end{array}$ \\
\hline $\begin{array}{l}\text { Bio- } \\
\text { Organic } \\
\text { Material }\end{array}$ & $\begin{array}{l}\text { Irregularly } \\
\text { shaped, high } \\
\text { greyscales (c. } \\
200-255)\end{array}$ & $\begin{array}{l}\text { Bio- } \\
\text { Organic } \\
\text { Material }\end{array}$ & $\begin{array}{l}\text { Irregularly } \\
\text { shaped, high } \\
\text { greyscales (c. } \\
200-255)\end{array}$ & $\begin{array}{l}\text { Bio- } \\
\text { Organic } \\
\text { Material }\end{array}$ & $\begin{array}{l}\text { Irregularly } \\
\text { shaped, high } \\
\text { greyscales (c. } \\
200-255)\end{array}$ \\
\hline
\end{tabular}

$\begin{array}{lll} & \text { Resin external } & \\ \text { Resin } & \text { to the floc } & \text { Resin } \\ \text { External to } & \text { matrix, grey- } & \text { External }\end{array}$

the Floc scale (c. $0-$ the Floc 20)

Low greyscale

Resin

(c. 7,00017,000)
Resin filled pores within the floc matrix, low grey-scale (c. $0-20$ ). NB

Resin

Filled

Pore-

Space only possible

to resolve

$$
\text { pores with }
$$

diameter $>30$

$\mu \mathrm{m}$ the Floc

NA

\begin{tabular}{|c|c|c|c|}
\hline $\begin{array}{l}\mu \mathrm{m} \text {-Scale } \\
\text { Pore }\end{array}$ & $\begin{array}{l}\text { Resin filled } \\
\text { pores within } \\
\text { the floc matrix, } \\
\text { low grey-scale } \\
\text { (c. } 0-20) \text {, } \\
\text { diameter <10 } \\
\mu \mathrm{m}\end{array}$ & $\begin{array}{l}\mu \mathrm{m} \text {-Scale } \\
\text { Pore }\end{array}$ & $\begin{array}{l}\text { Resin filled } \\
\text { pores within } \\
\text { the floc matrix, } \\
\text { low grey-scale } \\
\text { (c. } 0-20) \text {, } \\
\text { diameter < } 10 \\
\mu \mathrm{m}\end{array}$ \\
\hline $\begin{array}{l}\text { nm-Scale } \\
\text { Pores }\end{array}$ & $\begin{array}{l}\text { Resin filled } \\
\text { pores within } \\
\text { the floc matrix, } \\
\text { low grey-scale } \\
\text { (c. } 0-20) \text {, } \\
\text { diameter }>10 \\
\mu \mathrm{m}\end{array}$ & $\begin{array}{l}\text { nm-Scale } \\
\text { Pores }\end{array}$ & $\begin{array}{l}\text { Resin filled } \\
\text { pores within } \\
\text { the floc matrix, } \\
\text { low grey-scale } \\
\text { (c. } 0-20) \text {, } \\
\text { diameter }>10 \\
\mu m\end{array}$ \\
\hline
\end{tabular}




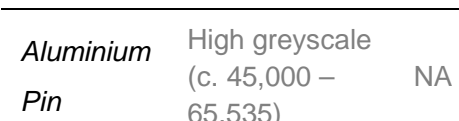

Pin $\quad 65.535)$

213 Table 1. Materials identified within the various 2D and 3D datasets, and the criteria used for their

214 identification/segmentation, e.g., size, morphology, and greyscale characteristics. Note, that the $\mu \mathrm{CT}$

215 are 16-bit and therefore have a pixel depth of 65,535 greyscales, whereas the SEM and STEM

216 imagery and FIB-nt data volumes are 8-bit with a 256 greyscale range.

Ultrathin-sections collected adjacent to the surface of the cross-section during ultramicrotomy were mounted on Formvar-covered copper grids (Gilder Grids) and coated in conductive carbon for STEM. STEM provided details of the pore space that cannot be obtained using SEM. Additionally, high-resolution elemental analysis via STEM X-ray spectroscopy (STEM-EDS) conducted on floc cross-section (SEMEDS) enabled the precise classification of individual floc constituents that cannot be achieved via SEM-EDS.

\subsection{Acquisition of Image Data}

\subsection{1. $\quad 3 D \mu C T$}

$\mu$ CT scans were performed using a Nikon Metrology XT-H 225 (Tokyo, Japan) micro-tomograph. This scanner was configured with a 25-225 kV 0-2000 $\mu \mathrm{A}$ X-ray source with tungsten reflection target capable of generating polychromatic X-rays

231 (focal spot size, c. $3 \mu \mathrm{m}$ ), and a Perkin Elmer (Waltham, Massachusetts, USA) 16-bit

232 flat-panel detector. Scan parameters were set to optimise contrast and resolution

233 (voltage $150 \mathrm{kV}$; current $160 \mu \mathrm{A}$; acquisition time between projections $2829 \mathrm{~ms}$ ) with

2342 -frame averaging. Maintaining the same scan parameters for all $\mu C T$ scans ensured comparability between datasets. The greyscale values of resulting 
projections represented differences in X-ray energy attenuation, related to material density and the attenuation coefficient of the materials being imaged.

\subsubsection{D SEM, STEM and EDS}

2D SEM image montaging (block-face SEM) was conducted using an FIB-SEM (FEI

Quanta 3D FEG, Hillsboro, Oregon, USA) fitted with a low-kV backscattered electron

detector. Backscattered electron (BSE) images were collected at $3 \mathrm{kV}$ accelerating

voltage and $4 \mathrm{nA}$ beam current to minimise the electron beam interaction volume and improve the spatial resolution of the BSE signal. Greyscale contrast of BSE images typically reflects composition. Systematic imaging of the floc cross-section generated 100's of images (pixel resolution, c. $30-60 \mathrm{~nm}^{2}$ ). Images were subsequently stitched together into montages using the Grid/Collection Stitching plugin in open source software FIJI/ImageJ (Preibisch et al. 2009). obtained using an FEI Inspect-F SEM fitted with a split field STEM detector (Hillsboro, Oregon, USA) and equipped with an Oxford Instruments (Oxford, UK) INCA X-act energy dispersive X-ray spectrometer. For low-resolution SEM-EDS mapping of the entire floc cross-section and high-resolution elemental mapping of Rol (see section 2.3) an accelerating voltage of $10 \mathrm{kV}$ (counting period, $10-30 \mathrm{~min}$ ). Counting periods varied between Rol and were selected to minimise damage to the sample surface. Dark-field STEM imaging of the ultrathin-sections was achieved at an accelerating voltage of $30 \mathrm{kV}$. Point spectra (STEM-EDS) were obtained from individual particles, at an accelerating voltage of $10 \mathrm{kV}$. 
3D FIB-nt was performed using a FIB-SEM (FEI Quanta 3D FEG, Hillsboro, Oregon,

USA) following the protocol outlined by Bushby et al. (2011). This relied on using the automated serial sectioning and imaging software Slice \& View software (FEI Hillsboro, Oregon, USA). Experimentation revealed an accelerating voltage of $30 \mathrm{kV}$ and a current of $0.5-5 \mathrm{nA}$ for the ion beam to be optimal for milling. Images were captured using the BSE signal detector operated at a voltage of $3 \mathrm{kV}$ and current of $4 \mathrm{nA}$, selected to match those used for 2D SEM (see section 2.4.2). The accuracy of FIB-nt relies on the stability of the FIB during milling and its ability to maintain regular intervals (i.e. slice thicknesses) between consecutive slices. An automated correction algorithm was applied during the serial sectioning procedure, which reduces or eliminates drift phenomena.

\subsubsection{Reconstruction and Segmentation of the 3D Data}

274 The product of $\mu \mathrm{CT}$ and FIB-nt are 2D projections/images of the sample/volume of interest that must be reconstructed to generate $3 \mathrm{D}$ volumes for visualisation and quantification. The reconstruction of $\mu \mathrm{CT}$ datasets was conducted using CTPro 3D (Nikon, Tokyo, Japan). Each scan generated 1,609 raw X-ray projections, yielding volumes with dimensions of $1,024 \times 1,024 \times 1,024$ voxels (voxel size resolution, 10 $\mu \mathrm{m}^{3}$ ). During reconstruction artefacts (e.g., beam hardening, Ketcham \& Carlson 2001) were addressed by the application of specific algorithms. FIB-nt datasets were reconstructed following the protocol outlined by Bushby et al. (2011) using 
- 600 images. During setup for FIB-nt the mill thickness was adjusted to match the

pixel resolution of the images, ensuring an isotropic voxel size suitable for quantitative analysis (Bushby et al. 2012).

\subsubsection{Visualisation and Quantification of the Correlative Datasets}

289 The quantification and visualisation of both $\mu \mathrm{CT}$ and FIB-nt datasets was conducted in in FIJI/ImageJ and required material segmentation, i.e. the classification of material phases based on greyscale values and/or shape, a critical stage in image processing (Cnudde \& Boone 2013). Segmentation was achieved via greyscale thresholding or using a semi-automated segmentation tool plugin (Trainable WEKA Segmentation, TWS v2.1.0) capable of machine learning (Arganda-Carreras et al. 2017). The choice between these segmentation methods was guided by appraisal of dataset complexity, including the number of bulk phases and the overlap between phase greyscale envelopes common in natural environmental materials. Resulting binary volumes were then quantified using the 3DRoiManager plugin (Ollion et al. 2013), which provided quantitative measurements of material properties, e.g., size, shape and greyscale intensities etc.

\subsubsection{Co-Registration of Datasets}

303 The process of aligning multiscale datasets (i.e. co-registration) is a critical aspect of

304 the correlative workflow, allowing information obtained using different imaging modalities and different spatial scales to be directly related. Co-registration of the multiscale 2D/3D datasets was achieved in the visualisation software Avizo (FEI Visualisation Sciences Group, Berlin, Germany). The success of registration is 308 dependent upon the identification of fiducial markers in the different datasets. Co- 
309 registration of $\mu \mathrm{CT}$ datasets relied upon the identification of the aluminium wire

310 implanted within the resin block, whilst internal landmarks (e.g., silt particles, bacteria

311 etc.) were used in the co-registration of higher resolution 2D and 3D datasets. Fig. 1

312 shows the sequence of steps taken to co-register the correlative datasets. Coarse

313 alignment was manually conducted using the Transform Editor tool within Avizo,

314 while fine registration was conducted automatically using the Landmark Surface

315 Warp module applied using a rigid transformation algorithm.

\section{3. Results and Discussion}

\section{3.1. Overview of the Multiscale Datasets}

\subsubsection{D Floc Sub-mm Structure and Internal Density}

320 Volumetric renderings of three floc samples (FS1, FS2 and FS3) generated based

321 on the $\mu \mathrm{CT}$ data (resolution, c. $10 \mu \mathrm{m}^{3}$ ) are shown in Fig. 2. For each 3D reconstruction greyscale contrast (16-bit pixel depth, e.g., 65,536 greyscales) between the flocs, surrounding resin and aluminium fiducial markers was sufficient to allow segmentation based on simple thresholding. This is illustrated in Fig. 1a and b that show cross-sectional greyscale images taken from the reconstructed $\mu C T$ scan of FS1, in which the floc and surrounding resin are easily distinguishable. Scan parameters were kept constant for each of the flocs, and thus datasets are directly comparable. Table 1 details the criteria (e.g., greyscale range, size and shape etc.) for identify the different material phases; i) resin ii) floc, and iii) aluminium registration

330 pin. The result of the segmentation procedure was a binary masks which formed the basis for subsequent visualisations and quantitative analysis (Fig. 2 and Table 2). 

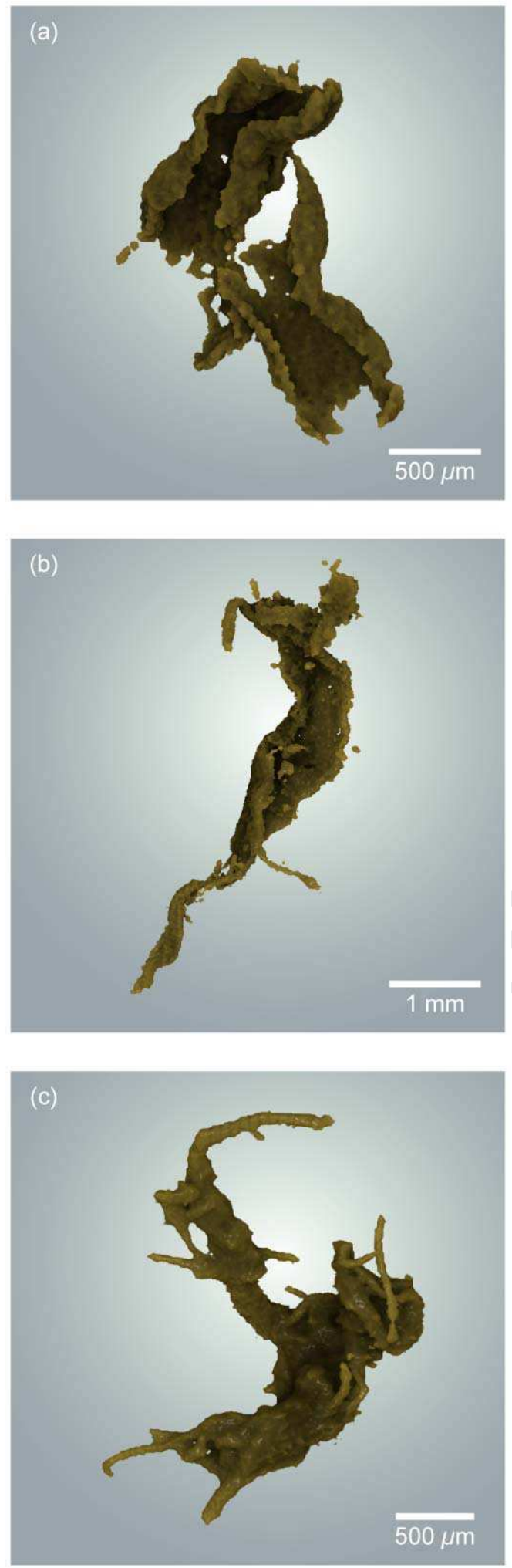

Figure 2. 3D visualisations of the floc samples FS1 (a) and FS2 (b) and FS3 (c) generated in Drishti from X-ray $\mu \mathrm{CT}$ data.

334 Descriptions of floc diameter $(D)$ and height to width ratios $(\mathrm{H} / \mathrm{W})$ were made using 335 the Feret diameter, i.e. the distance between two parallel planes enclosing an object. 
336 Based on these the floc samples can be described as macroflocs ( $D>160 \mu \mathrm{m}$;

337 Manning \& Dyer 2002) that exhibit elongate $(H / W>2: 1)$ and highly contorted

338 morphologies. Flocs FS2 and FS3 exhibit filamentous protuberances projecting

339 beyond their peripheries, likely related to the presence of cyanobacteria (confirmed

340 by SEM, STEM and FIB-nt dataset, see sections 3.1.2, 3.1.3 and 3.1.4). FS1 was

341 observed to differs significantly from FS2 and FS3, being composed of three distinct

342 sub-units, connected by narrow linkages c. $\leq 30 \mu \mathrm{m}$. Each of the floc samples

343 exhibited regions of high and low X- ray attenuation (Table 1 and Fig. $2 \mathrm{c}$ and Fig. S2

344 of Supplementary Materials). The distribution of regions of high attenuating elements

345 within floc FS2 are shown in a 3D rendering in Fig. S2 of Supplementary Materials.

346 This information provided a means of identifying Rol for further analysis (see Section

$347 \quad 3.1 .2$ and Fig. 3a-c and Fig. S3 of Supplementary Materials).

348

\begin{tabular}{lllllll}
\hline Floc & Floc & \multicolumn{2}{l}{ Feret Diameter $(\mu \mathrm{m})$} & \multirow{2}{*}{ H/W } \\
\cline { 3 - 5 } Sample & $\begin{array}{l}\text { Volume } \\
\left(\mu \mathrm{m}^{3}\right)\end{array}$ & Major & Intermediate & Minor & \\
\hline FS1 & $1.95 \times 10^{8}$ & 2414.54 & 1298.65 & 631.29 & $3: 1$ \\
FS2 & $5.04 \times 10^{8}$ & 11183.83 & 755.82 & 266.06 & $4: 1$ \\
FS3 & $2.44 \times 10^{8}$ & 945.03 & 800.19 & 323.23 & $2: 1$
\end{tabular}

349 Table 2. 3D quantitative measures of floc geometry (volume and Feret diameter) and 350 shape (height/width ratio).

3.1.2. 2D Floc Micrometre-Structure and Composition Revealed in Cross-Section

354 Fig. 3c shows the 2D SEM-BSE image montage collected from the cross-section of

355 floc FS1 (resolution, c. $60 \mathrm{~nm}^{2}$ ), (FS2, resolution, c. $30 \mathrm{~nm}^{2}$ and individual SEM-EDS 
356 elemental maps are shown in Fig. S2 and Fig. S4 respectively). Similar to $\mu \mathrm{CT}$,

357 greyscale contrast (8-bit pixel depth, e.g., 256 greyscales) was sufficient to allow

358 flocculated material to be segmented from surrounding resin. However, the higher

359 resolution of SEM also enabled the recognition of additional floc components, which

360 could be classified based on particle size, shape and greyscale value and further

361 validated by comparison with SEM-EDS elemental maps. Four additional materials

362 were identified; i) resin filled pore-space, ii) floc matrix (e.g., clays, unicellular

363 bacteria, organo-mineral debris), iii) individual non-clay mineral grains (e.g., quartz,

364 feldspar and mica) and iv) large bio-organic and organic structures (e.g., organic

365 detritus, diatoms, cyanobacteria) (Table 1 and Fig. $3 d$ ). Particles $<10 \mu m$ (e.g., EPS,

(a)

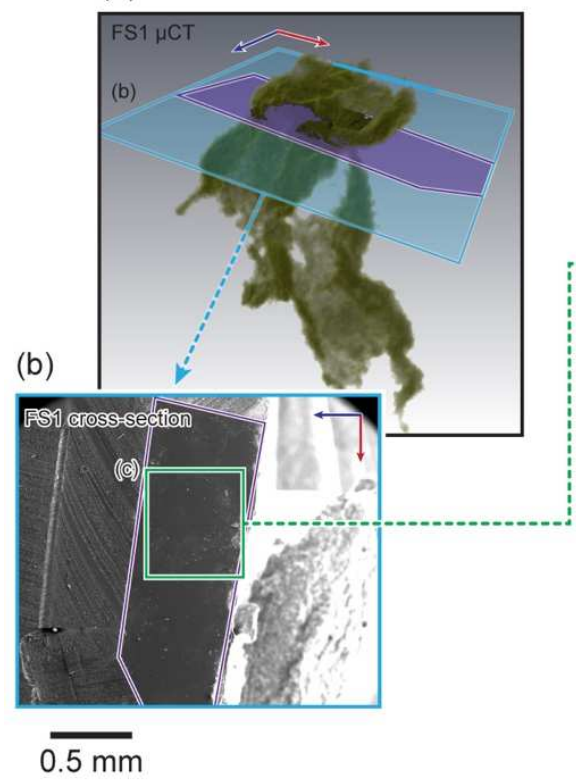

(c)

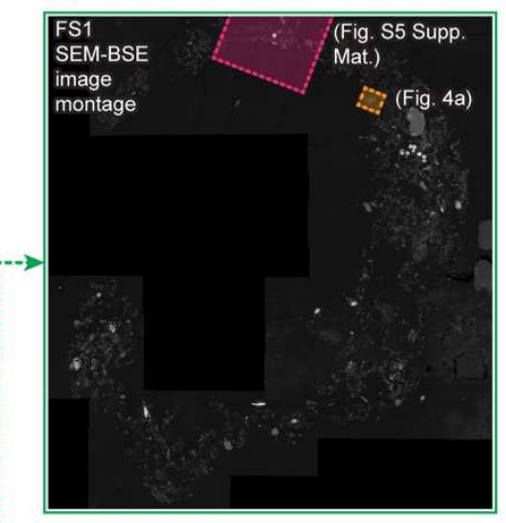

$\overline{100 \mu \mathrm{m}}$

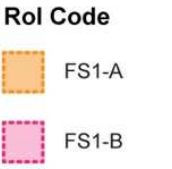

(d)

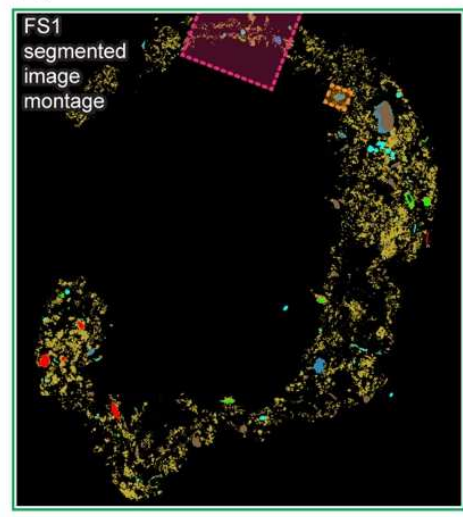

$\overline{100 \mu \mathrm{m}}$

Figure 3. Analysis of the cross-section located in floc FS1. The location of the cross-section created within FS1 is shown in (a) and the region of the cross-section containing the floc is shown in (b). The trapezoidal shape of the sectioned block is highlighted in purple both in (a) and (b), while the boundary of the SEM image of the cross-section shown in (b) is defined in 3D space in (a) in blue. The SEM-BSE image montage (c) obtained from the cross-section through floc FS1 enabled the identification of floc constituents (d) and characterisation of floc structure in 2D. The locations of Rol selected for further analysis are shown in (c) and (d). 
clay minerals and unicellular bacteria) could not be accurately segmented and were identified collectively as 'floc matrix'. The floc matrix is likely to be compositionally complex, however, SEM-EDS revealed strong signals for Fe, Al/Si and Si (Fig. S4 of Supplementary Materials), indicating the presence of iron oxyhydroxides, clay minerals and silicates. Constituents were unevenly distributed within the floc matrix, with regions of low occupation characterised by high porosity and low greyscale values (c. $<50)$ and regions of high occupation exhibiting low porosity and high greyscale values (c. >70) (Fig. 3 and Table 1).

Non-clay mineral grains were differentiated based on their blocky/irregular morphology, uniform greyscale and elemental signature ( $\mathrm{Si}, \mathrm{Fe})$. In comparison, bioorganic material and biota could be identified relatively easily based on their high greyscale values (c. $200-255)$ due to heavy metal (Pb, Os and U) staining (see also elemental phase map, Fig. S4 of Supplementary Materials). Strong signals for $\mathrm{Pb}$, Os and $\mathrm{U}$ related to heavy metal-stained organics, typically large features (diameter, $>10 \mu \mathrm{m}$ ) such as cyanobacteria and organic detritus, while an associated signal of Si (blue) was indicative of eukaryotic plankton (e.g., diatom, foraminifera).

\subsubsection{D Submicrometre and Nanometre Structure and Composition of}

\section{Selected Rol}

For each floc several Rol were identified based on structural and/or compositional characteristics revealed in SEM-BSE imagery and SEM-EDS elemental maps (see Section 3.1.2). Fig. 3 and Fig. S3 of Supplementary Materials show the locations of Rols selected for FS1 and FS2 respectively. Rols were targeted to either characterise further floc nm composition and particle-particle interactions via STEM, 

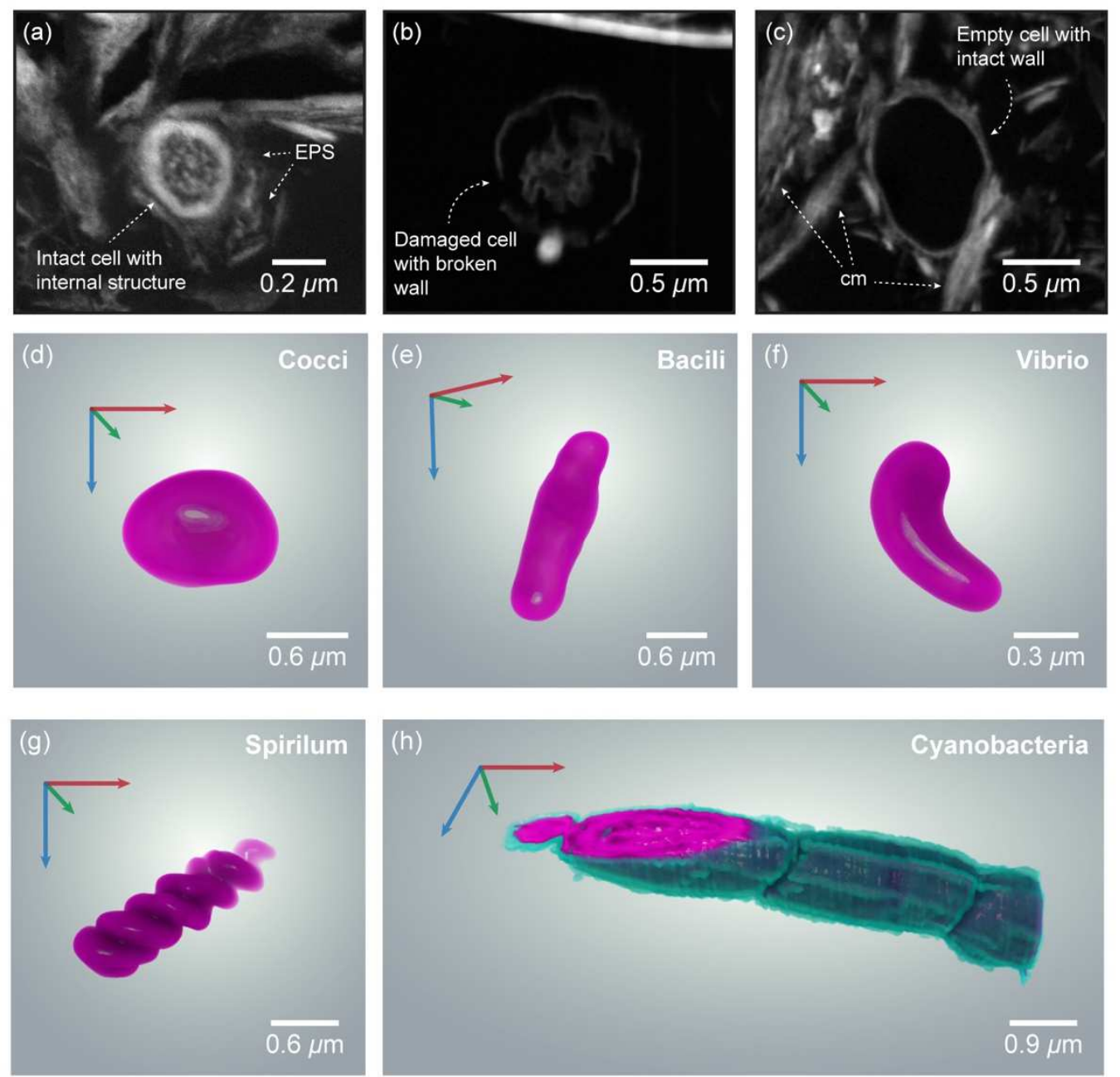

Figure 5. Characterisation of bacterial cells. $(a-c)$ STEM images showing examples of the three categories of intracellular integrity used as an indicator of the fidelity of stabilised flocs to their original structure. $(d-g)$ Examples of different bacterial cellular morphologies reconstructed based on 3D FIB-nt data. (a) intact bacteria displaying an undamaged cell wall, cytoplasm (grainy structure) and nucleoplasm (denser region towards the centre of the cell); (b) damaged bacterial cell with a broken cell wall and degraded cytoplasm and/or nucleoplasm; (c) empty cell lacking plasma. (d) cocci, (e) bacilli, (f) vibrio, (g) spirillum and (h) cyanobacteria.

391 (resolution, c. $25-30 \mathrm{~nm}^{2}$ ) and STEM (resolution, c. $5-10 \mu \mathrm{m}^{2}$ ) imagery and

392 corresponding SEM-EDS elemental maps are shown in Fig. 4 and Fig. S5 of

393 Supplementary Materials. 
The four main floc constituents (pore-space, floc matrix, non-clay mineral

grains, and large bioorganic and organic structures) were also identified in SEM-BSE and STEM imagery. However, the higher resolution enabled further distinction between materials within the floc matrix: i) clay minerals, ii) microbial cells, iii) organo-mineral debris, and iv) EPS (Table 1). Microbial cells could be easily identified due to their high greyscale values (c. $>200$ ) and differential staining of subcellular structures (Fig. S5 of Supplementary Materials). High-resolution STEM imagery revealed internal/external cell structure allowing the classification of microbes based on their metabolic state (Heissenberger et al. 1996) as: i) intact, ii) damaged and iii) empty (e.g., Fig. $5 a-c)$. Whilst the resolution of SEM imagery prevented the detection of EPS $2-20 \mathrm{~nm}$ in diameter (Leppard 1992), its presence is confirmed by STEM imagery (Fig. S6 of Supplementary Materials). EPS was observed to be closely associated or 'bound' to the cell walls of metabolically active microbes, whilst 'soluble' EPS exuded by microorganisms was found throughout the floc matrix and often associated with clay minerals (Fig. S6 of Supplementary Materials).

To investigate density variations within the floc matrix (see Section 3.1.2, Fig. 3 and Figs. S3 and S4 of Supplementary Materials), Rols FS1-A and FS2-B (Fig. 4a and e) were selected to encompass regions exhibiting high and low occupation. Within both high and low occupation regions clay minerals were rarely observed in isolation, but were observed in units of 10's of particles. STEM imagery revealed several common particle associations, including units of clay platelets aligned faceto-face and/or edge to face, and clay minerals arranged around a central bacterium (Fig. S6 of Supplementary Materials). Low density regions of the floc matrix mainly consisted of particle associations arranged in open, 'card-house' structures, and 
were highly porous (Fig. 4a). STEM showed the nanometre pore space between primary particles filled with exopolymeric material, whilst EPS was notably absent in the larger micrometre pore channels (Fig. S6 of Supplementary Materials). In comparison, high density areas consisted primarily of closely packed clay minerals dispersed with pyrite (Fe+S) (Fig. 4c), and had a lower porosity and high organic signal (Fig. 4d).

\subsubsection{D Submicrometre-Structure and Composition of Selected Rol}

Volumetric renderings of two FIB-nt volumes obtained from FS2, labelled FS2-A and FS2-B and corresponding to the Rol of the same name (see Fig. 4e and Fig. S5 of

Supplementary Materials), are shown in Figs. 6 and 7 respectively. The large volume size of FS2-A (c. $8 \times 10^{4} \mu \mathrm{m}^{3}$, voxel size c. $67 \mathrm{~nm}$ ) enabled the organisation of large submicrometre structures to be revealed in $3 \mathrm{D}$, while the higher resolution of FS2-B constituents and particle-particle associations. primary floc constituents (resin filled pore-space, floc matrix, non-clay minerals, and large bioorganic and organic structures) and floc matrix constituents (clays minerals, microbial cells and organo-mineral debris) identified in 2D SEM and STEM were also identified in FIB-nt (Table 1 and Fig. 6 and 7). Additionally, the enhanced spatial resolution of FS2-B enabled the segmentation of closely packed particles c. $<2 \mu \mathrm{m}$ 440 (e.g., clays within the floc matrix), enabling their reconstruction in 3D (Fig. 7e). This 441 is demonstrated in Fig. 7d in which individual clays can be discriminated in 2D slices 442 from the FIB-nt dataset. Several of the particle-particle associations identified within 443 SEM and STEM data (see Section 3.1.3 and Fig. S6 of Supplementary Materials) 


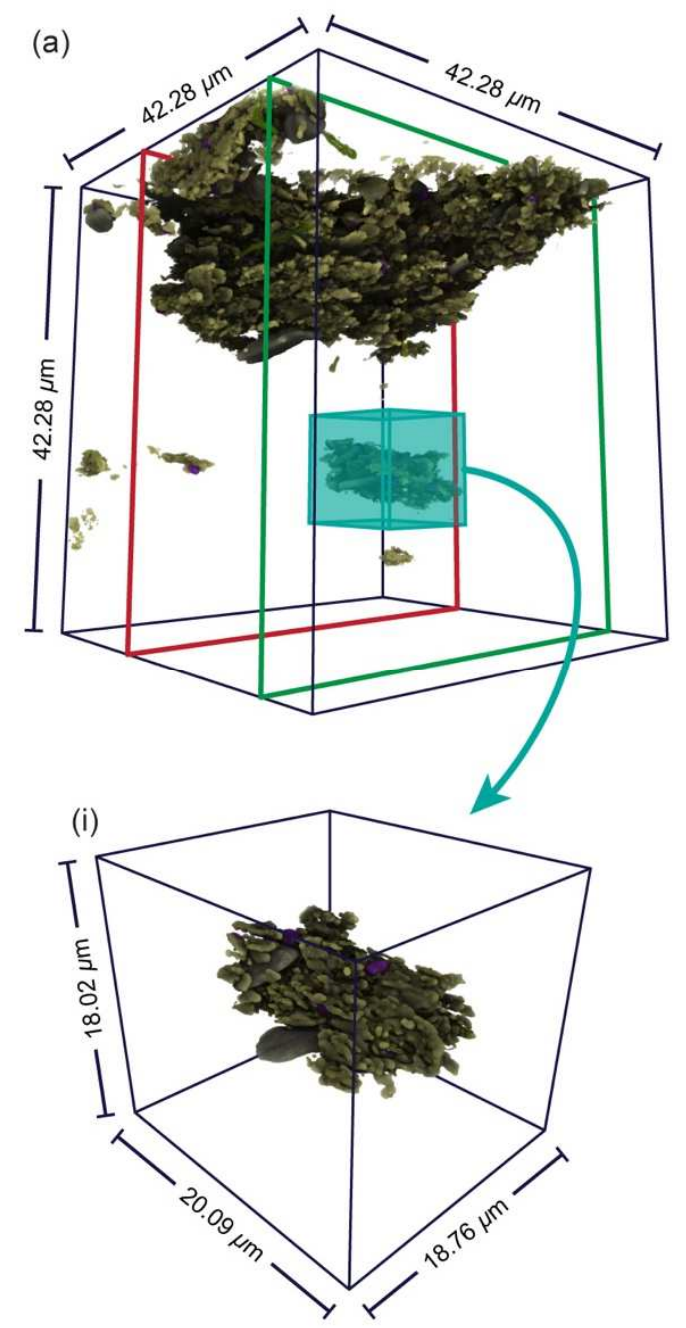

(b)

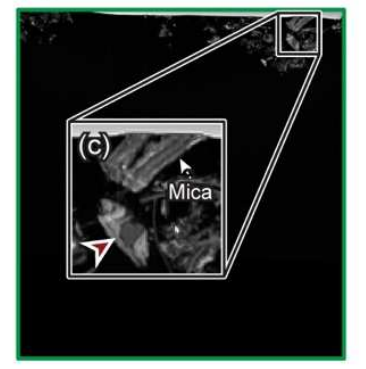

$$
\overline{20 \mu \mathrm{m}}
$$

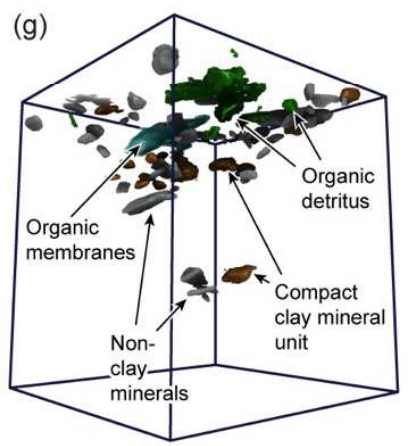

Floc Components

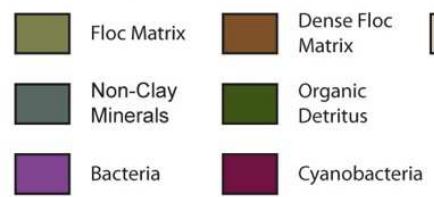

(d)
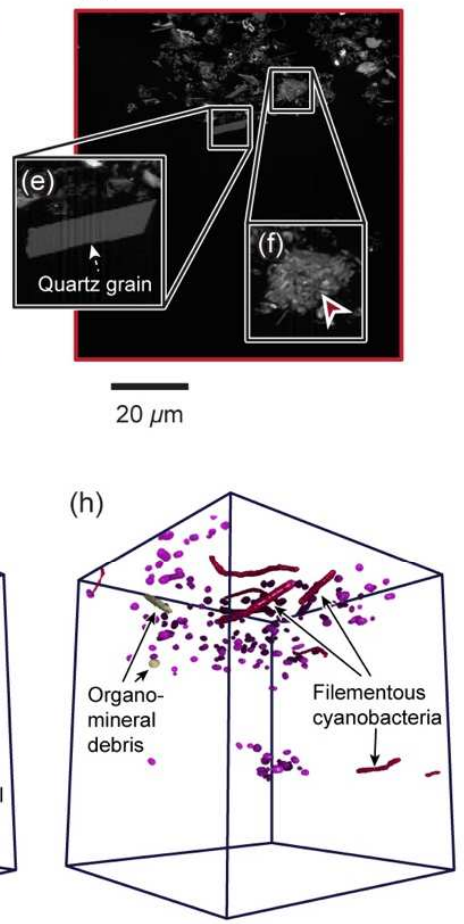

Organo-Mineral Detritus \& Zoo Plankton

Figure 6. 3D reconstructions of the FIB-nt volume Rol FS2-A: (a) 3D rendering of the segmented components identified within FS2-A; (b - c) Selected BSE images from the FIB-nt dataset illustrating the differences in grey-scale and morphology that enable feature segmentation, note the red arrow shown in (c) highlights a region of high particle occupation. The locations from which the 2D BSE images shown in (b) and (c) were taken from within the FIB-nt dataset are indicated by coloured lines shown in (a); (g) Same as (a) but with selected materials rendered transparent to reveal the non-clay minerals, organic membranes and amorphous organic detritus; (h) Same as (a) but with certain materials rendered transparent to reveal the individual bacteria, cyanobacteria and organomineral debris (diatom frustules); e) ) Sub-volume taken for FS2-A showing an isolated microfloc (location indicated in (a)).

444 were also identified in FS2-B. Visualised in 3D these structures are revealed to be discrete units, separable from surrounding floc matrix by nanopores (Fig. 7e and f). 
446 Fig. 7e shows a particle association consisting of clay minerals aligned face-to-face,

447 while Fig. $7 f$ shows clay particles aligned around a central bacterium. Examination of

448 the floc matrix reveals micrometre pore channels delineating the boundaries of

449 discrete structural units 10's $\mu \mathrm{m}$ in diameter (e.g., Fig. 6i). These structures usually

450 consist of several particle-particle associations and larger primary particles (e.g., silt

451 grains, organic detritus), loosely arranged in an open, card-house structure, linked

452 together by filamentous cyanobacteria.

Quantification reveals the occupied volume of FS2-A largely consists of

inorganic material, with clays accounting for c. $98 \%$ of occupied space and non-clay

minerals c. $0.5 \%$ (Table 3 ). In contrast, a larger proportion of FS2-B is occupied by organics, which accounted for c. $34 \%$ of the occupied volume compared to inorganic material, c. $66 \%$. Within both FIB-nt datasets micrometre pore channels can be identified together with elongated nanopores throughout the floc matrix (Fig. 6 and 7). Combined, these give a total porosity of c. $95 \%$ and c. $52 \%$ for FS2-A and FS2-

$B$ respectively. The resolution and 3D nature of the datasets enabled the classification of microbial cells based on morphotype (Dazzo \& Niccum 2015) and five categories were recognised: i) cocci, ii) regular straight rods (e.g., bacilli), iii) curved/U-rods (e.g., vibrio), iv) spirals (e.g., spirilla) and v) unbranched filaments (e.g., cyanobacteria) (Fig. 6d - h). Cocci were characterised as near spherical (length/width, $<2: 1$ ) with diameters $<1.5 \mu \mathrm{m}$ (Fig. 6h), frequently forming groups of several cells. In comparison, bacilli exhibited a straight, rod-like morphology

467 (length/width, <16:1) and were larger (diameter, c. $2 \mu \mathrm{m}$ ). Cells with a crescent curvature (comma-shaped) were identified as vibrio, and had similar dimensions to bacilli (Fig. $5 d-h$ ). Although observed less frequently, spirilla were classified as elongated cells displaying a distinctive repeated waveform (e.g., corkscrew-shaped). 
(a)

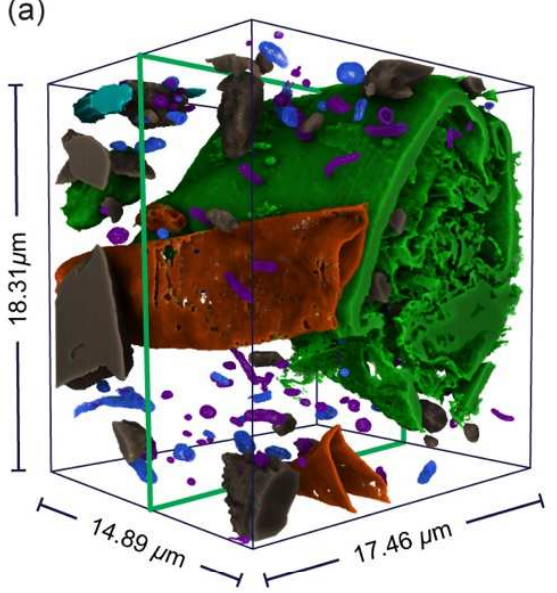

(b)

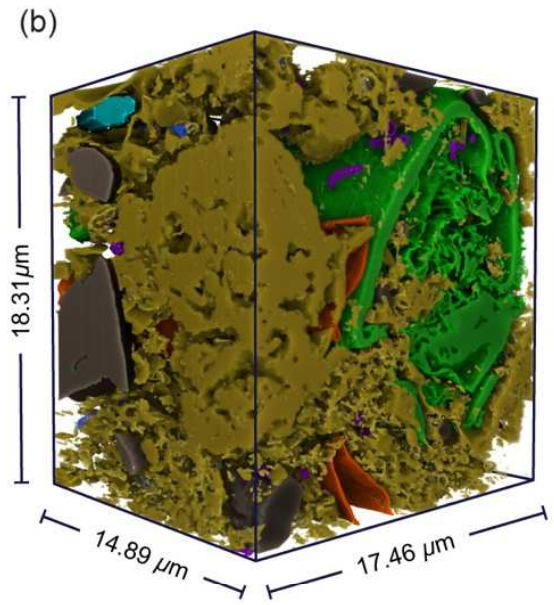

(f)

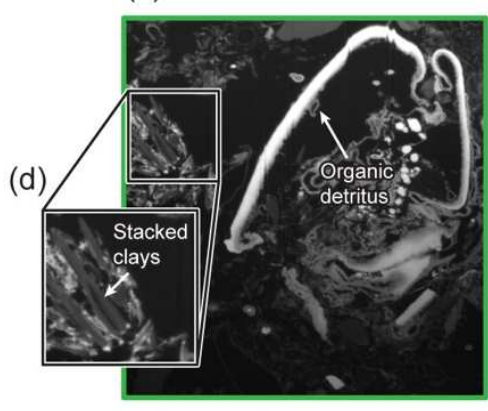

$5 \mu \mathrm{m}$ (e)

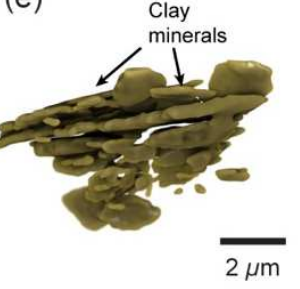

Floc Components

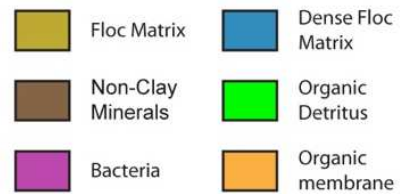

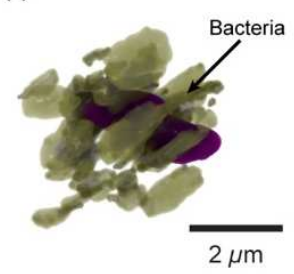

Organo-Mineral

Detritus \& Zoo Plankton

Cyanobacteria

Figure 7. 3D reconstructions of the FIB-nt volume Rol FS2-B: (a) 3D rendering of the segmented components identified within FS2-B; (c) Selected BSE image from the FIB-nt dataset illustrating the differences in grey-scale and morphology that enable feature segmentation. The locations from which the 2D BSE image shown in (c) was taken from within the FIB-nt dataset are indicated by the green coloured line shown in (a); (d) Sub-set from (c) showing clay minerals aligned face-to-face and/or edge-to-face; (e) 3D reconstruction of (d); (f) Clay particle arranged radially around a bacterial cell (bacteria false-coloured purple).

471 Filamentous (cyanobacteria) bacteria could be easily distinguished from other cell

472 types based on elongated shape (length/width, >16:1), and were present in a

473 number of forms, ranging from cells $1-2 \mu \mathrm{m}$ in diameter to larger varieties

474 (diameters, c. $>3 \mu \mathrm{m}$ ) (Fig. 5h). The quantities of cell morphotypes and their

475 intracellular integrity (e.g., intact, damaged or empty, Heissenberger et al. 1996) are 476 shown in Table 4. 


\begin{tabular}{|c|c|c|c|c|c|c|c|c|}
\hline \multirow{3}{*}{$\begin{array}{l}\text { FIB-nt } \\
\text { Sample }\end{array}$} & \multirow{3}{*}{$\begin{array}{l}\text { Total } \\
\text { Volume } \\
\left(\mu \mathrm{m}^{3}\right)\end{array}$} & \multicolumn{7}{|c|}{ Floc Constituents (Vol. \%) } \\
\hline & & \multicolumn{2}{|c|}{ Porosity } & \multicolumn{3}{|c|}{ Floc Matrix } & \multicolumn{2}{|c|}{ Other } \\
\hline & & $\begin{array}{l}\text { Micro- } \\
\text { Porosity }\end{array}$ & $\begin{array}{l}\text { Nano- } \\
\text { Porosity }\end{array}$ & $\begin{array}{l}\text { Clay } \\
\text { Minerals }\end{array}$ & Bacteria & $\begin{array}{l}\text { Organo- } \\
\text { Mineral } \\
\text { Debris }\end{array}$ & $\begin{array}{l}\text { Organic } \\
\text { Detritus }\end{array}$ & $\begin{array}{l}\text { Non- } \\
\text { Clay } \\
\text { Minerals }\end{array}$ \\
\hline FS2-A & C. $8 \times 10^{4}$ & 91.4 & 3.80 & 4.08 & 0.07 & 0.01 & 0.23 & 0.41 \\
\hline FS2-B & c. $5 \times 10^{3}$ & - & 51.79 & 31.96 & 0.45 & 0.07 & 17.16 & 2.15 \\
\hline
\end{tabular}

Table 3. Volume fractions for the segmented components of FIB-nt datasets FS2-A and FS2-B.

\begin{tabular}{|c|c|c|c|c|c|c|c|c|}
\hline \multirow{2}{*}{$\begin{array}{l}\text { FIB-nt } \\
\text { Sample }\end{array}$} & \multirow{2}{*}{$\begin{array}{l}\text { Total } \\
\text { Bacteria } \\
\text { (Count) }\end{array}$} & \multicolumn{2}{|c|}{$\begin{array}{l}\text { Intracellular } \\
\text { Integrity (\% of Total } \\
\text { Count) }\end{array}$} & \multicolumn{5}{|c|}{ Cell Morphotype (\% of Total Count) } \\
\hline & & $\begin{array}{l}\text { Intact } \\
\text { Cells }\end{array}$ & $\begin{array}{l}\text { Damaged } \\
\text { and } \\
\text { Empty } \\
\text { Cells }\end{array}$ & Cocci & $\begin{array}{l}\text { Regular } \\
\text { Straight } \\
\text { Rod }\end{array}$ & $\begin{array}{l}\text { Curved/U- } \\
\text { Rod }\end{array}$ & $\begin{array}{l}\text { Unbranched } \\
\text { Filament }\end{array}$ & Spiral \\
\hline FS2-A & 239 & 73.2 & 26.8 & 48.95 & 28.03 & 17.57 & 5.44 & 0 \\
\hline FS2-B & 118 & 76.4 & 23.6 & 41.53 & 32.20 & 19.49 & 4.24 & 2.54 \\
\hline
\end{tabular}

480 Table 4. Total count of bacteria, numbers of intact, damaged and empty cells and

481 proportions of different cell morphotypes identified in FIB-nt datasets FS2-A and 482 FS2-B.

\subsection{Validation of Floc Stabilisation Method}

486 Interpretation and quantification of 3D flocs relies on an assumption that the

487 characteristics observed are representative of true floc structure and not artefacts of sampling, storage and preparation (Liss et al. 1996; Wheatland et al. 2017). The correlative workflow demonstrated above permits the validation of floc integrity in this context by enabling observation of 3D floc structure across multiple spatial scales. 
Fluid exchanges and sample dehydration are essential for the chemical

492 stabilisation process, but can result in the distortion and/or rupture of delicate cellular

493 structures. While a number of cells identified in the 3D FIB-nt datasets were

494 classified as either damaged or empty (Heissenberger et al. 1996) (Table 4),

495 Wheatland et al. (2017) notes that the presence of damaged cells in itself is not

496 indicative of inadequate stabilisation, since active microbial communities contain

497 cells of all states of life including decay. More diagnostic of the state of preservation

498 is the presence of intact cells, as rupture due to poor stabilisation would be expected

499 to be systemic. Within the FIB-nt datasets intact cells accounted for c. $>50 \%$ of the

500 total number of cells, a higher percentage compared than that of the total number of

501 metabolically active bacteria usually found in natural microbial communities (c.

$502<30 \%$, Ward \& Johnson 1996). The loss of soluble EPS (i.e. EPS unassociated with

bacterial cells) from the floc matrix during fluid exchanges can result in severe

504 perturbation (Leppard et al. 1996). Previous studies have estimated up to $50-80 \%$ of

505 EPS can be removed in certain instances from the floc matrix following stabilisation

506 (Leppard et al. 1996), with the primary effect on the floc being the rearrangement of

507 primary particles and compression of floc structures (recorded as shrinkage) (Liss et

508 al. 1996). STEM imagery obtained from the floc samples reveals the presence of

509 exopolymeric material, observed as dense networks in the nanometre pore space

510 between primary particles (e.g., clays and bacteria) and distributed throughout the

511 floc matrix (Fig. S6 of Supplementary Materials). This suggest that the little

512 extraction of the EPS network within the floc matrix has taken place. The use of

513 plankton chambers for floc capture and agarose gel for floc immobilisation help

514 minimise the destructive forces associated with traditional sampling methods (e.g.,

515 floc breakage via pipetting) (Droppo et al. 1996). However, morphological changes 
516 can result if flocs interact once settled, e.g., false aggregation of flocs and/or

517 pseudoplastic contortion of delicate structures with overburden pressure.

518 Examination of flocs of immobilised in agarose prior to resin embedding provides a

519 means of assessing the degree of interaction between neighbouring flocs. 2D cross-

520 sectional images taken from the $\mu \mathrm{CT}$ of test sample FS0 (Fig. S1 of Supplementary

521 Materials) reveal minimal overlap between neighbouring floc particles, suggesting

522 morphological changes to be minimal. This is supported by the 3D visualisation of

523 individual flocs (FS1, FS2 and FS3, Fig. 3 and Movie 1) that indicate delicate

524 structures (e.g., filamentous protuberances, Fig. 3b and c) remained intact following

525 settling and during the addition of agarose and sub-sampling for stabilisation.

\subsection{Merits of the Correlative Workflow}

528 This imaging workflow enables for the first time floc composition and 3D structure to

529 be investigated at all relevant spatial scales, from primary particles to entire flocs

530 several $\mathrm{mm}$ in size. This represents a significant advance in our ability to

531 characterise flocs, filling the resolution gap between traditional imaging techniques

532 (e.g., TEM, CLSM and COM) (Fig. 8).

533 The success of the workflow critically depends upon the quality (i.e. resolution,

534 signal-to-noise ratio) and degree of similarity (i.e. resolution and mechanisms for

535 contrast generation) between the different datasets (Caplan et al. 2011; Handschuh

536 et al. 2013). Image quality is of particular importance, since it determines the

537 accuracy with which features can be identified, segmented and quantified. Within

$538 \mu \mathrm{CT}$ and EM datasets the boundaries between objects are not always well defined,

539 but can consist of a transitional zone $3-5$ pixels wide (Holzer et al. 2014;

540 Wheatland et a. 2017). Depending on the pixel/voxel resolution of the dataset the 


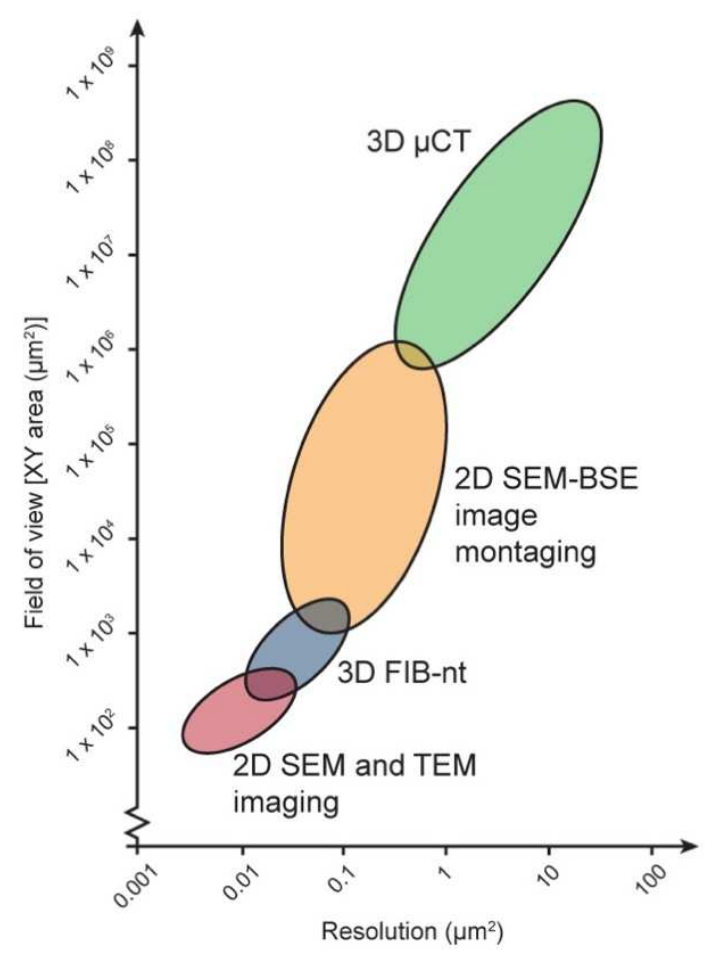

Figure 8. Length-scales over which the 2D and 3D imaging techniques employed within correlative workflow operate, with corresponding typical cross-section (XY) and resolution achievable by each technique. Note that the imaging methods used overlap, enabling truly correlative examination of floc structure from the $\mathrm{nm}$ to $\mathrm{mm}$-scale.

541 maximum error is usually considered to be half the width of this zone. Further

542 discussion regarding the process of segmentation and potential errors is outlined in

543 Wheatland et al. (2017). 
Fig. 3 shows the correlative 2D and 3D datasets collected from FS1 registered 
545 in a single 3D scene. To locate the floc cross-section, aluminium wire was used as a 
546 fiducial marker to register the $\mu \mathrm{CT}$ data collected after ultramicrotomy to the original 
$547 \mu \mathrm{CT}$ dataset of the intact flocs (see Section 2.3 and Fig. 1d). Segmentation of the 
548 aluminium wire would ideally result in it being represented by similar number voxels

(a)

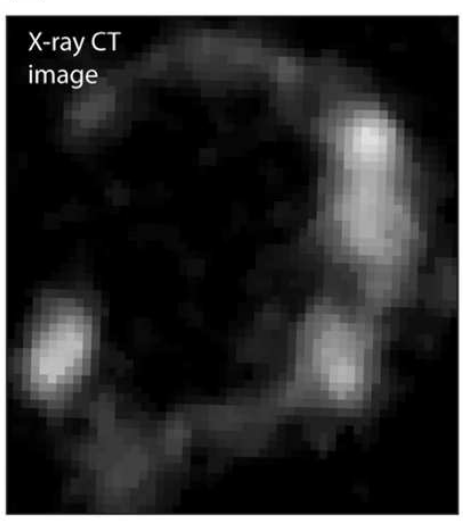

$\overline{100 \mu \mathrm{m}}$

(b)

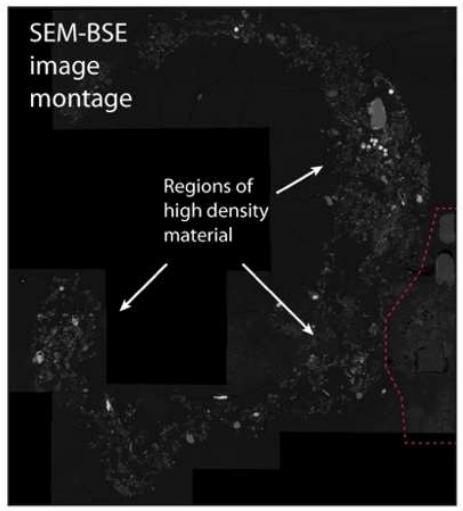

$\overline{100 \mu \mathrm{m}}$

(c)

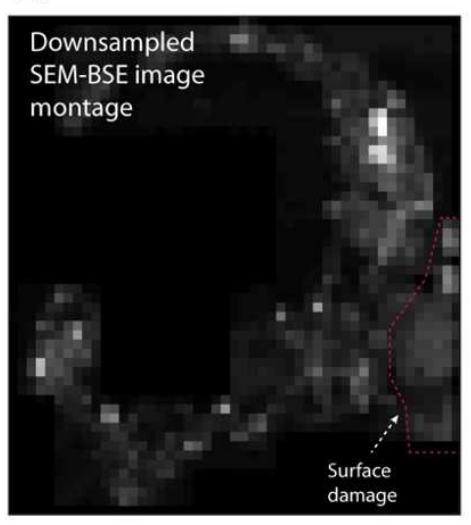

$\overline{100 \mu \mathrm{m}}$

Figure 9. Comparison of $\mu C T$ with SEM-BSE. Down-sampling the pixel size of the SEM-BSE image montage (c) to match that of the $\mu \mathrm{CT}$ data $(\mathrm{c} .10 \mu \mathrm{m})$, enabled comparison between the SEM-BSE image montage (b) and corresponding $\mu \mathrm{CT}$ slice (a). This provides a means of validating the potential floc structures responsible for different greyscale values within the $\mu \mathrm{CT}$ dataset. Regions of the floc observed to contain high concentrations highlighted in (b) of particles in the BSE-SEM image montages were shown to exhibit high grey-scale values in the $\mu \mathrm{CT}$ dataset (a). 
549 in the corresponding $\mu \mathrm{CT}$ datasets. Within both pairs of $\mu \mathrm{CT}$ data the wire was easily

550 segmented from other material phases based on its high greyscales (e.g., see

551 Section 3.1.1 and Fig. 2). However, discrepancies in the size of the segmented

552 aluminium wire were observed $-1.6 \%$ for FS1 and $3.8 \%$ for FS2 - which likely

553 resulted from scan artefacts, i.e. secondary edge effects due to partial volume effect.

554 Assuming an even distribution of the extraneous voxels around the surface area of the aluminium fiducial marker, the minimum offset between co-registered datasets can be estimated to be of the order of less than a voxel (c. $3-6 \mu \mathrm{m})$ over a total 3D size of $10 \times 10^{8} \mu \mathrm{m}$. With evidence of only minor peripheral misalignment of the registered datasets, the co-registration of the 3D $\mu C T$ scans has been successful. 2D SEM-BSE image montages of the floc cross-sections were critical for the co-registration of $2 \mathrm{D}$ and $3 \mathrm{D} \mathrm{nm}$ and $\mu \mathrm{m}$ datasets with the sub mm-scale $3 \mathrm{D} \mu \mathrm{CT}$ data. The trapezoidal shape of the cross-sections (Fig. 3b and Fig. S3 of

Supplementary Materials) can be defined in the $\mu$ CT datasets, enabling the SEMBSE image montages to be tied to the surface within an accuracy of $3-6$ voxels (c. $30-60 \mu \mathrm{m})$. However, further confidence in the accuracy of the co-registration can be obtained by comparing the actual shape of the floc boundary depicted in the two datasets. Reducing the pixel resolution of the SEM-BSE image montages (i.e. downsampling) to match that of the $\mu \mathrm{CT}$ datasets (c. $10 \mu \mathrm{m}$ ) enables a direct comparison between the SEM-BSE image montages and $\mu \mathrm{CT}$ data (Fig. 9), which indicates the error to be less than a voxel (c. $<10 \mu \mathrm{m})$. In addition, the features responsible for the

570 variations observed in $\mu \mathrm{CT}$ greyscale values, that reflect the variability of floc constituents and structure at the sub-voxel scale (representing the impact of partial

572 volume effects, cf. Ketcham \& Carlson 2001), can be confirmed by comparing the

573 down-sampled SEM-BSE image montage with the corresponding $\mu$ CT slice. Fig. 9 
demonstrates that regions of the SEM-BSE image montage identified as containing

575

576

577

578

579

580

581

582

583

584

585

586

587

588

589

590

591

592

593

594

595

596

597

598

high concentrations of particles correspond to regions of high attenuation (high greyscales) within $\mu \mathrm{CT}$. The similar imaging conditions selected for both SEM-BSE imaging (montaging and imaging of Rol) and FIB-nt allowed reference landmarks within the corresponding datasets to be recognised with a high degree of certainty $(20-60 \mathrm{~nm})$. As the contrast mechanisms in both SEM-BSE and dark-field STEM are similar (related to atomic number) fiducial markers internal to the floc (e.g., silt grains and bacteria etc.) could be easily identified. However, inspection of the overlaid STEM images following co-registration with SEM imagery revealed discrepancies in the positions of these markers. These displacements are likely the result of ultramicrotomy, as shear stresses imposed during sectioning are known to cause thin-section compression (Peachey 1958).

\subsection{Applications of 3D Floc Structural and Compositional Data}

Providing such detailed 3D analysis of flocs is not readily applicable for field scale quantification of suspended sediment aggregates. However, this technique has the potential, through targeted experimental or field campaigns, to provide new understanding of floc composition and controls on floc characteristics and structures. For example, these datasets quantify 3D floc characteristics (e.g., size, shape and porosity) that are critical input parameters to cohesive sediment transport models.

Additionally, the datasets demonstrate the complex structural associations and particle-particle interactions found at different spatial scales and levels of aggregation. These are frequently hypothesised in the literature or inferred from 2D observations of gross floc characteristics (e.g., Maggi et al. 2007; Lee et al. 2011). These particle-particle associations reflect the materials present in suspension 
599 during floc development and their interactions. Here, the particle associations

600 including clays oriented face-to-face and/or edge-to-face likely occur due to a

601 combination of electrochemical interactions (i.e. cohesion), and the additional

602 binding forces provided by organic materials resulting in bioflocculation, i.e. adhesion

603 (Liss et al. 1996; Righetti \& Lucarelli 2010). Yet the short distances $\left(10^{1}\right.$ to $\left.10^{3} \mathrm{~nm}\right)$

604 over which these forces (cohesion and adhesion) operate mean that these structures

605 are clearly scale-dependent. Larger structural units consisting of several particle-

606 particle associations and individual primary particles (e.g., silt grains, amorphous

607 organic detritus etc.) were found throughout the floc samples. Therefore, this new

608 method could provide data to challenge or validate simplified descriptors of floc

609 structure e.g., self-similarity or fractal geometry (e.g., Khelifa \& Hill 2006).

610 Our data also demonstrate and quantify the microbial associations with

611 flocculated material. For example, demonstrating the importance of cell morphotype

612 on floc shape and strength. Here, filamentous cyanobacteria cross-link smaller

613 structural units (observed in 2D SEM and 3D FIB-nt) promoting interactions between

614 these structural units and providing structural connectivity and flexibility (e.g.,

615 Nguyen et al. 2007). Their strongly elongate shape and propensity to align has a

616 strong influence on floc development, promoting the growth of non-spherical flocs.

617 Additionally, filaments extending from the periphery of the flocs provide anchor

618 points to facilitate floc growth through interactions with other flocs (Burger et al 619 2017).

620

621 4. Conclusion

622 The development of a novel correlative workflow provides datasets demonstrating

623 the complex composition and multiscale 3D structure of aquatic sediment flocs. This 
624 work provides the most detailed floc structural analysis to date and provides the following specific advantages:

- 2D and 3D imaging techniques can be applied in a systematic manner to successfully obtain a complete set of overlapping, co-registered datasets from a single floc sample. The resultant datasets enable the identification and quantification of floc composition and structures across multiple length-scales. This approach improves on traditional 2D correlative microscopy by providing truly correlative datasets that are quantifiable.

- The orientation of multi-scale and multi-modal datasets in 3D space presents a significant challenge, but can be successfully overcome using fiducial markers. This is reliant on selecting imaging techniques that share similar contrast mechanisms, to ensure that landmark features can be detected at different spatial scales.

- Particle-particle and structural associations can be directly related across length-scales. Structures that are scale-dependent can be recognised, providing further evidence for interactions that have previously been hypothesised. The imaging workflow therefore provides a means of obtaining quantitative measures of floc composition and structure and a better understanding of the mechanisms promoting floc growth.

- The correlative workflow is adaptable, and the potential exists for further research to design targeted experiments to explore relationships between floc structure and behaviour, controls on floc stability and structure, and floc microbial communities.

\section{Acknowledgements}


J.A.T.W. would like to thank the Engineering and Physical Sciences Research

650 Council for the award of a scholarship and the Queen Mary University of London

651 Postgraduate Research Fund. K.L.S, A.J.B and S.J.C acknowledge the Natural

652 Environmental Research Council (NE/N011678/1) for funding. Jemima Burden (MRC

653 Laboratory for Molecular Cell Biology, University College London) is thanked for her 654 help with sample preparation.

655

656

\section{References}

Agrawal, Y.C., Pottsmith, H.C. 2000. Instruments for particle size and settling velocity observations in sediment transport. Mar. Geol. 168 (1-4), 89-114.

Arganda-Carreras, I., Kaynig, V., Rueden, C., Eliceiri, K.W., Schindelin, J., Cardona, A., Seung, H.S. 2017. Trainable Weka Segmentation: a machine learning tool for microscopy pixel classification. Bioinformatics 33 (15), 24242426.

Azam, F., Long, R.A. 2001. Sea snow microcosms. Nature 414, 495-498.

Burd, A.B. Jackson, G.A. 2009. Particle aggregation. Annu. Rev. Mar. Sci. 1, 65-90.

Burger, W., Krysiak-Baltyn, K., Scales, P.J., Martin, G.J.O., Stickland, A.D., Gras, S.L. 2017. The influence of protruding filamentous bacteria on floc stability and solid-liquid separation in the activated sludge process. Water Res. 123, 578585.

Burnett, T.L., McDonald, S.A., Gholinia, A., Geurts, R., Janus, M., Slater, T., Haigh, 
672 Bushby, A.J., Png, K.M.Y., Young, R.D., Pinali, C., Knupp C., Quantock A.J. 2011. imaging three-dimensional tissue architectures by focused ion beam scanning electron microscopy. Nat. Protoc. 6 (6), 845-858.

Bushby, A.J., Mariggi, G., Armer, H.E.J., Collinson, L.M. 2012. Correlative Light and Volume EM: Using Focused Ion Beam Scanning Electron Microscopy to image transient events in model organisms. Methods Cell Biol. 111, 357-382.

Caplan, J., Niethammer, M., Taylor, R.M., Czymmek, K.J. 2011. The power of correlative microscopy: multi-modal, multi-scale, multi-dimensional. Curr. Opin. Struct. Biol. 21 (5), 686-693.

681 Cnudde, V., Boone, M.N. 2013. High-resolution X-ray computed tomography in geosciences: A review of the current technology and applications. Earth-Sci. Rev. 23, 1-17.

Dazzo F.B., Niccum, B.C. 2015. Use of CMEIAS image analysis software to accurately compute attributes of cell size, morphology, spatial aggregation and color segmentation that signify in situ ecophysiological adaptations in microbial biofilm communities. Computation 3, 72-98.

Droppo, I.G. 2001. Rethinking what constitutes suspended sediments. Hydrol.

690 Droppo, I.G. 2003. A new definition of suspended sediment: implications for the 691 measurement and prediction of sediment transport. In: Bogen, J., Fergus, T., 692 Walling, D. (Eds.), Erosion and Sediment Transport Measurement in Rivers: 693 Technological and Methodological Advances. IAHS Publication No. 249, 694 International Association of Hydrological Sciences, Wallinford, pp. 238. 
Droppo, I.G., Flannigan, D.T., Leppard, G.G., Jaskot, C., Liss, S.N. 1996. Floc stabilization for multiple microscopic techniques. Appl. Environ. Microbiol. 62, 3508-3515.

Handschuh, S., Baeumler, N., Schwaha, T., Ruthensteiner, B. 2013. A correlative approach for combining microCT, light and transmission electron microscopy in a single 3D scenario. Front. Zool. 10, 1-16.

Heissenberger A., Leppard, G.G., Herndl, G.J. 1996. Relationship between the intracellular integrity and the morphology of the capsular envelope in attached and free-living marine bacteria. Appl. Environ. Microbiol. 62 (12), 4521-4528.

Holzer, L., Indutnyi, F., Gasser, P.H., Münch, B., Wegmann, M. 2004. Threedimensional analysis of porous $\mathrm{BaTiO} 3$ ceramics using FIB nanotomography. J. Microsc. 216 (1), 84-95.

Jarvis, P., Jefferson, B., Gregory, J., Parsons, S.A. 2005. A review of floc strength and breakage. Water Res. 39 (14), 3121-3137.

Ketcham, R.A., Carlson, W.D. 2001. Acquisition, optimization and interpretation of Xray computed tomographic imagery: applications to the geosciences. Comput. Geosci. 27, 381-400.

Khelifa, A. Hill, P.S. 2006. Models for effective density and settling velocity of flocs. J. Hydraul. Res. 44, 390-401.

Lee, B.J., Toorman, E., Molz, F., Wang, J., 2011. A two-class population balance equation yielding bimodal flocculation of marine or estuarine sediments. Water Res. 45, 2131-2145.

Leppard, G.G. 1992. Size, morphology and composition of particulates in aquatic ecosystems: solving speciation problems by correlative electron microscopy. The Analyst 117 (3), 595-603. 
Leppard, G.G., Heissenberger, A., Herndl, G.J. 1996. Ultrastructure of marine snow. 289-298.

723

724

725

726

727

728

729

730

731

732

733

734

735

736

737

738

739

740

741

742

Liss, S.N. 2002. Microbial Flocs Suspended Biofilms. In: Bitton, G. (Ed.), Encyclopaedia of Environmental Microbiology (Vol. 4). John Wiley and Sons, New York, NY, pp. 2000-2012.

Liss, S.N., Droppo, I.G., Flannigan, D.T., Leppard, G.G. 1996. Floc architecture in wastewater and natural riverine systems. Environ. Sci. Technol. 30 (2), 680686.

Maggi, F., Mietta, F., Winterwerp, J.C. 2007. Effect of variable fractal dimension on the floc size distribution of suspended cohesive sediment. J. Hydrol. 343 (1-2), 43-55.

Manning, A.J., Dyer, K.R. 2002. The use of optics for the in situ determination of flocculated mud characteristics. J. Opt. A-Pure Appl. Op. 4, 71-81.

Nguyen, T.H., Tang, F.H., Maggi, F. 2017. Optical Measurement of cell Colonization Patterns on Individual Suspended Sediment aggregates. J. Geophys. Res. Earth Surf. $122(10)$, 1794-1807.

Nguyen, T.P., Hankins, N.P., Hilal, N. 2007. A comparative study of the flocculation behaviour and final properties of synthetic and activated sludge in wastewater treatment. Desalination 204 (1), 277-295.

Ollion, J., Cochennec, J., Loll, F., Escudé, C., Boudier, T. 2013. TANGO: a generic tool for high-throughput 3D image analysis for studying nuclear organization. Bioinformatics 29, 1840-1841. 


\section{Journal Pre-proof}

743

744

745

746

747

748

749

750

751

752

753

754

755

756

757

758

759

760

761

762

763

764

765

766

O'Shea, F.T., Cundy, A.B, Spencer, K.L. The contaminant legacy from historic coastal landfills and their potential as sourcse of diffuse pollution. Mar. Pollut. Bull. 128, 446-455.

Peachey, L.D. 1958. Thin Sections: I. A study of section thickness and physical distortion produced during microtomy. J. Biophys. Biochem. Cytol. 4 (3), 233242.

Preibisch, S., Saalfeld, S., Tomancak, P. 2009. Globally optimal stitching of tiled 3D microscopic image acquisitions. Bioinformatics 25 (11), 1463-1465.

Righetti, M., Lucarelli, C. 2010. Resuspension phenomena of benthic sediments: the role of cohesion and biological adhesion. River Res. Appl. 26, 404-413.

Rummel, C.D., Jahnke, A., Gorokhova, E., Kühnel, D., Schmitt-Jansen, M. 2017. Impacts of Biofilm Formation on the Fate and Potential Effects of Microplastic in the Aquatic Environment. Environ. Sci. Technol. 4 (7), 258 - 267

Rusconi, R., Guasto, J. S., Stocker, R. 2014. Bacterial Transport Suppressed by Fluid Shear. Nat. Phys. 10 (3), 212-217.

Schindelin, J., Arganda-Carreras, I., Frise, E., Kaynig, V., Longair, M., Pietzsch, T., Preibisch, S., Rueden, C., Saalfeld, S., Schmid, B., Tinevez, J-Y., White, D. J., Hartenstein, V., Eliceiri, K., Tomancak, P., Cardona, A. 2012. Fiji: an opensource platform for biological-image analysis. Nature Methods 9 (7), 676-682.

Sharma, S., Lin, C-L., Miller, J.D. 2017. Multi-scale features including water content of polymer induced kaolinite floc structures. Miner. Eng. 101, 20-29.

Soulsby, R.L., Manning, A.J., Spearman, J., Whitehouse, R.J.S. 2013. Settling velocity and mass settling flux of flocculated estuarine sediments. Mar. Geol. 339, 1-12. 
Tolhurst, T.J., Gust, G., Paterson, D.M. 2002. The influence on an extra-cellular polymeric substance (EPS) on cohesive sediment stability. In: Winterwerp, J.C., Kranenburg, C. (Eds.), Fine Sediment Dynamics in the Marine Environment - Proceedings in Marine Science 5. Elsevier Science, Amsterdam, pp. $409-425$

Ward, A.K., Johnson, M.D. 1996. Heterotrophic microorganisms. In: Hauer, F.R., Lamberti, G.A. (Eds.), Methods in Stream Ecology. Academic Press, San Diego, CA, pp. 233-268.

Wheatland, J.A.T., Bushby, A.J., Spencer, K.L. 2017. Quantifying the structure and composition of flocculated suspended particulate matter using focused ion beam nanotomography. Environ. Sci. Technol. 51 (16), 8917-8925.

Winterwerp, J.C. 1998. A simple model for turbulence induced flocculation of cohesive sediment. J. Hyd. Eng. Res. 36 (3), 309-326.

Zhang, N., Thompson, C.E.L., Townend, I.H., Rankin, K.E., Paterson, D.M., Manning A.J. 2018. Nondestructive 3D imaging and quantification of hydrated biofilmsediment aggregates using X-ray microcomputed tomography. Environ. Sci. Technol. 52 (22), 13306-13313. 


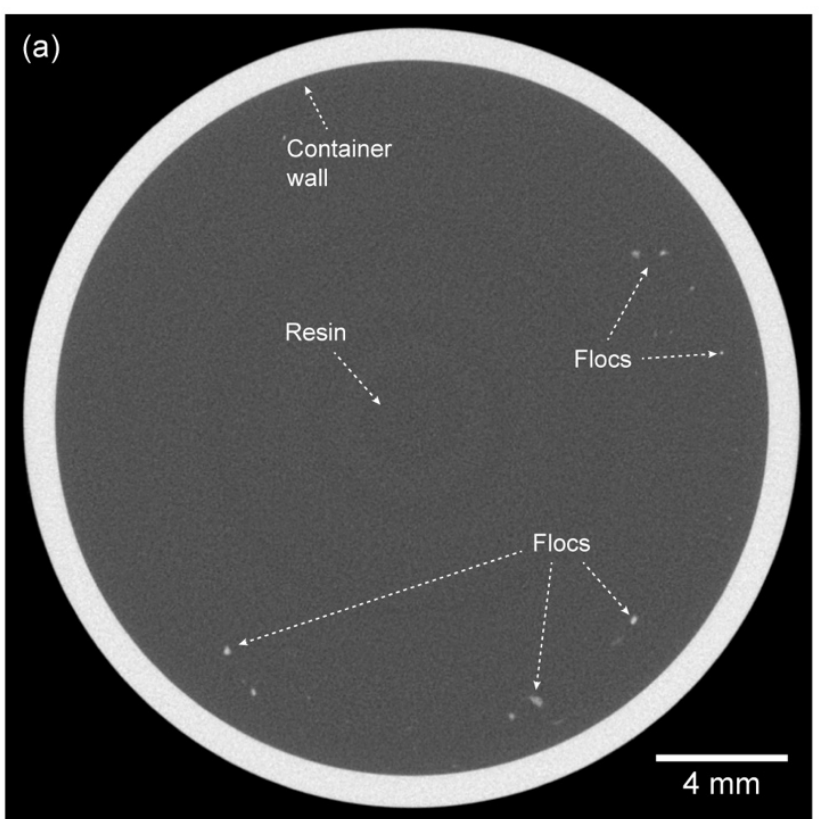

786

787 Supplementary Fig. S1. $\mu \mathrm{CT}$ cross-sectional image from the scan of test sample

788 FS0, note the minimal overlap between neighbouring floc particles.

789

790

791

792 
(a)

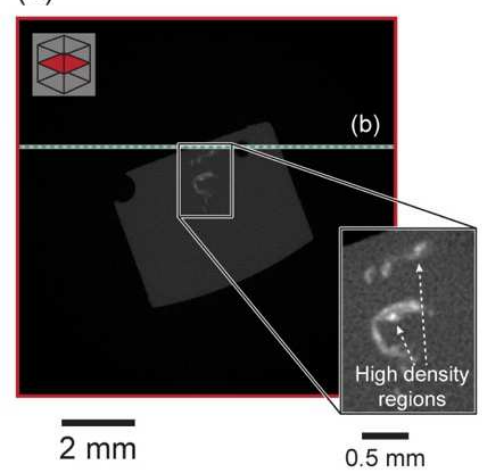

(b)

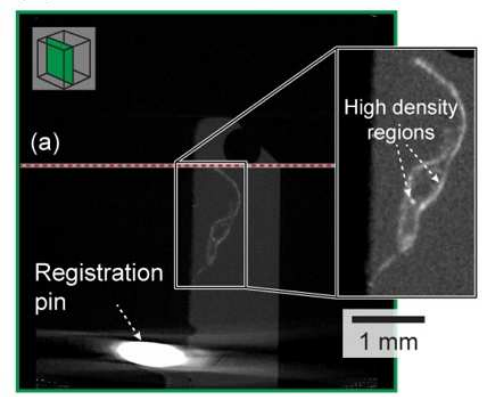

$\overline{2 \mathrm{~mm}}$ (c)

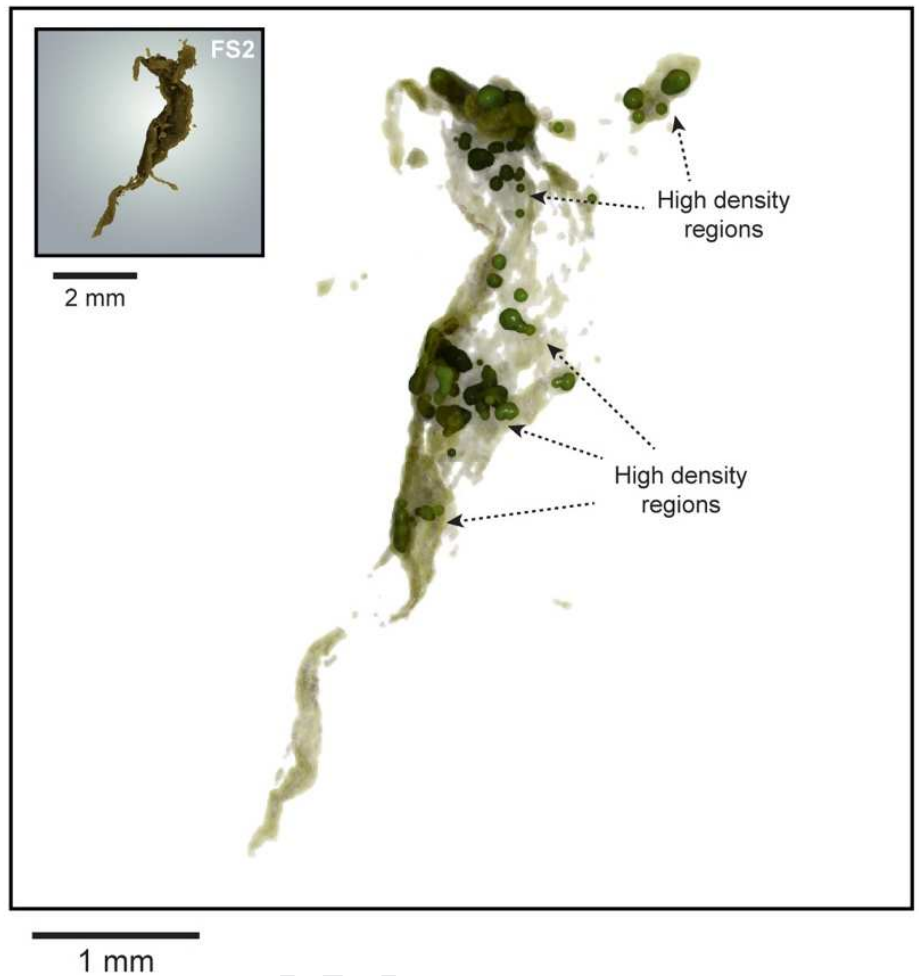

794 Supplementary Fig. S2. 3D visualisations of the floc samples FS2 (c). (a) and (b)

795 are image slices taken in two orthogonal planes from the $\mu \mathrm{CT}$ date; note the regions

796 of high and low X-ray attenuation within the floc shown in the magnified sub-sets; (c)

797 shows a 3D visualisation of floc FS2 but with the regions of low X-ray attenuation

798 rendered semi-transparent to reveal the regions of high attenuation. 
(a)

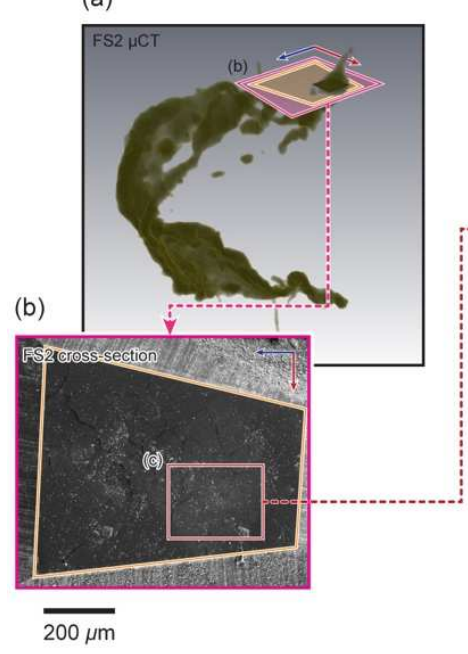

(c)

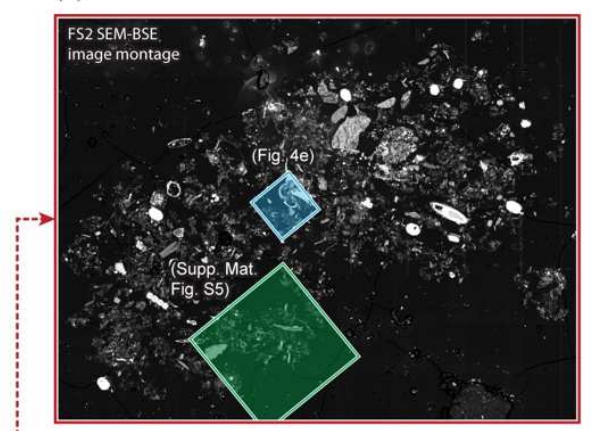

$50 \mu \mathrm{m}$

Rol Code

FS2-A

FS2-B

Floc Components

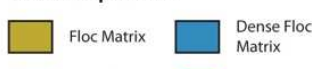

Non-Clay (d)

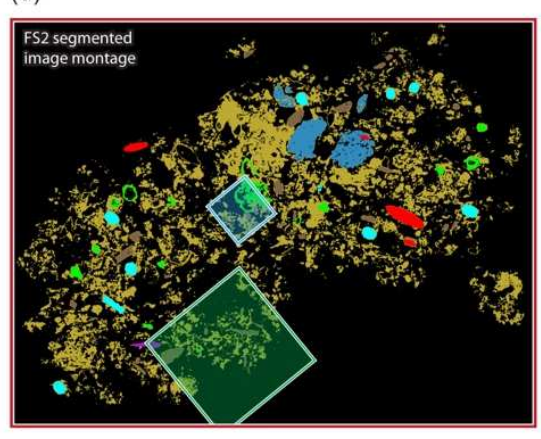

$50 \mu \mathrm{m}$ $\square$ Dense Floc
Matrix
$\square \quad$ Organic
Detritus

$\square$ Organo-Mineral

Detritus \& Zoo Plankton

Cyanobacteria

802 Supplementary Fig. S3. Analysis of the cross-section located in floc FS2. The

803 location of the cross-section created within FS2 is shown in (a) and the region of the

804 cross-section containing the floc is shown in (b). The trapezoidal shape of the sectioned block is highlighted in orange both in (a) and (b), while the boundary of the

806 SEM image of the cross-section shown in (b) is defined in 3D space in (a) in pink.

807 The SEM-BSE image montage (c) obtained from the cross-section through floc FS2

808 enabled the identification of floc constituents (d) and characterisation of floc structure

809 in 2D. The locations of Rols FS2-A and FS2-B selected for further analysis are

810 shown in $(\mathrm{c})$ and $(\mathrm{d})$.

811 


\section{Journal Pre-proof}

(a)

(b)
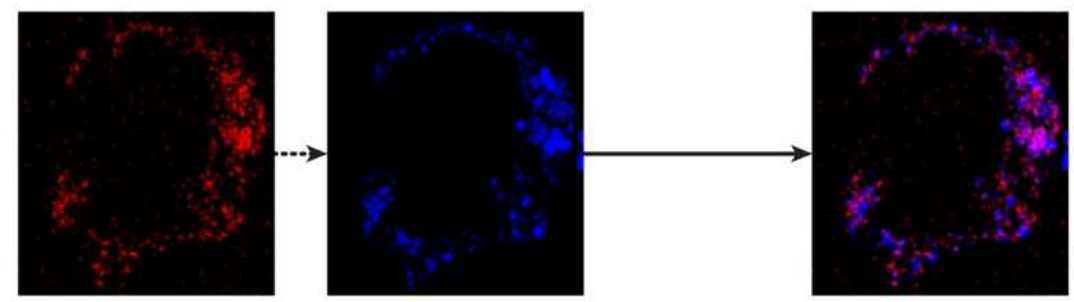

Al $0-3$

Si $0-12$

(c)

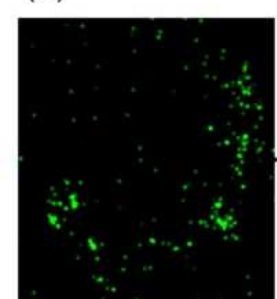

$\mathrm{Pb} \quad 0-3$

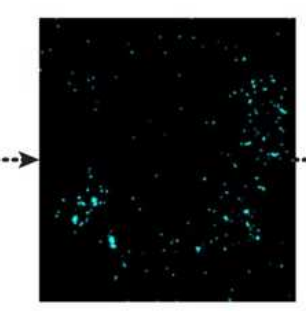

Os $0-3$

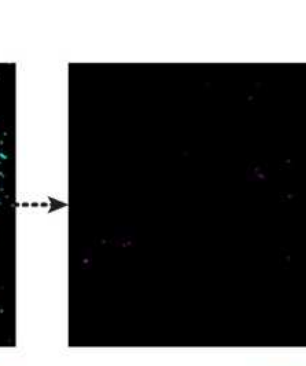

U $\quad 0-2$ (d)

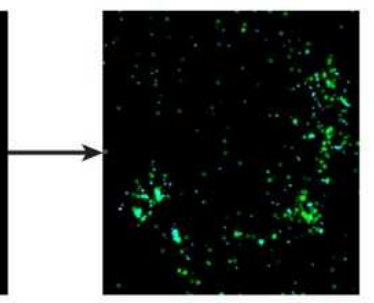

$\overline{200 \mu \mathrm{m}}$

812

Supplementary Fig. S4. Individual SEM-EDS elemental maps collected from the

814 cross-section through floc FS2. (a) Inorganic signals for Al and $\mathrm{Si}$; (b) combined

815 signal (phase map) for $\mathrm{Al}$ and $\mathrm{Si}$; (c) Organic signals for $\mathrm{Pb}$, Os, and $\mathrm{U}$; (d) combined

816 signal for $\mathrm{Pb}, \mathrm{Os}$, and $\mathrm{U}$.

817 
(a)

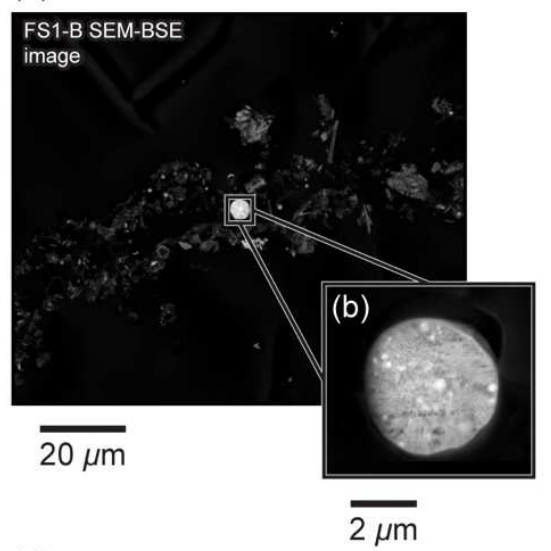

(d)

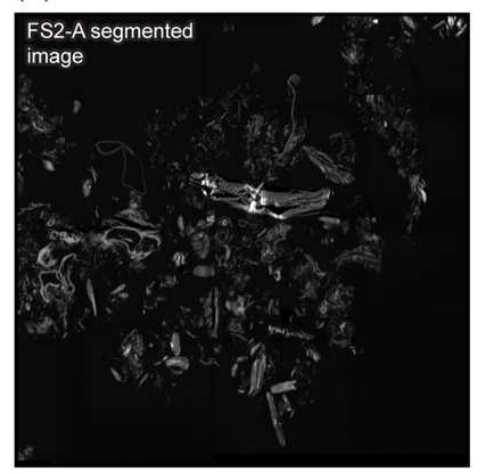

$\overline{5 \mu \mathrm{m}}$ (c)

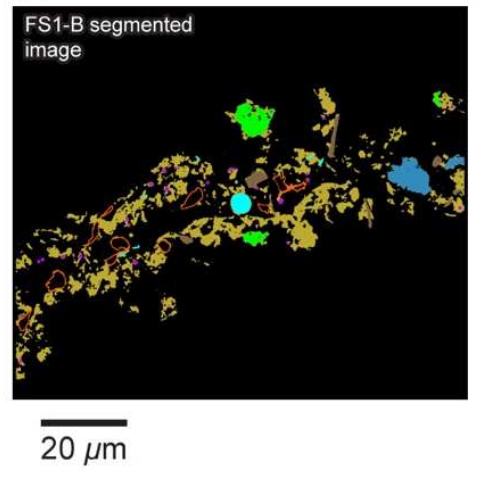

(e)

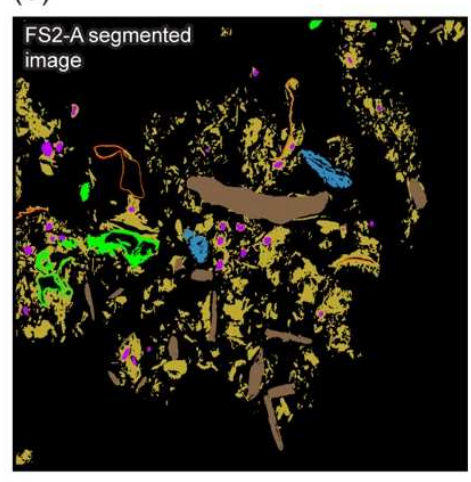

$\overline{5 \mu \mathrm{m}}$

Floc Components

$\square$ Floc Matrix

$\square \begin{aligned} & \text { Dense Floc } \\ & \text { Matrix }\end{aligned} \quad \square$ Bacteria

Organo-Mineral

Detritus \& Zoo Plankton

$\square$ Non-Clay

Minerals

Organic
Detritus

Organic membrane

Cyanobacteria

819 Supplementary Fig. S5. Characterisation of floc sub-micrometre composition and

820 structure in 2D within Rol FS1-B (a) and FS2-A (c). The locations of Rols FS1-B and

821 FS2-A are shown in Fig. 3c and Fig. S4 of Supplementary Materials respectively. (b)

822 shows a magnified subset from (a) that isolates a single cyanobacteria to

823 demonstrates how differential staining of subcellular structures has taken place. 
(a)

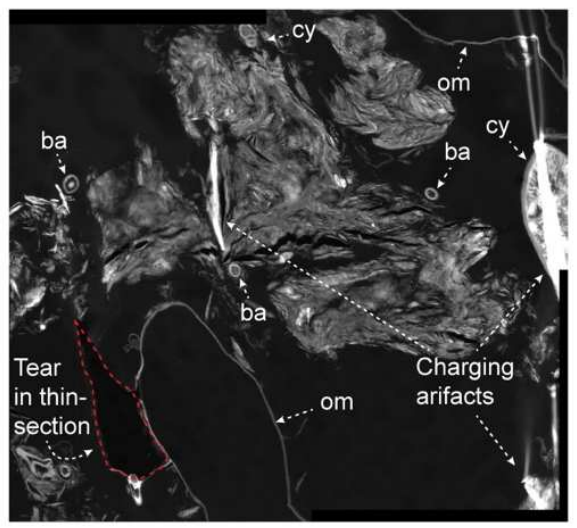

$\overline{2 \mu \mathrm{m}}$

(c)

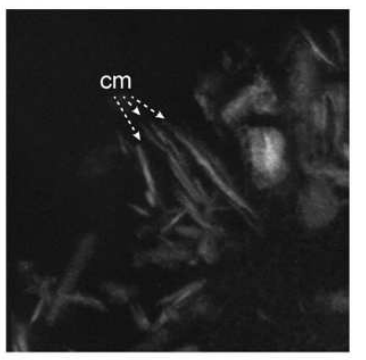

$\overline{0.4 \mu \mathrm{m}}$ (b)

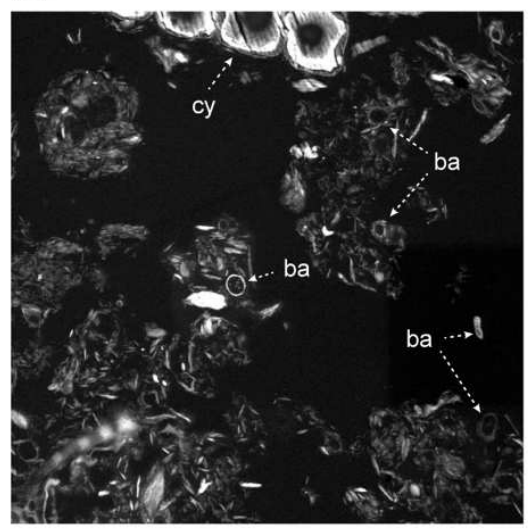

$\overline{2 \mu \mathrm{m}}$ (d)

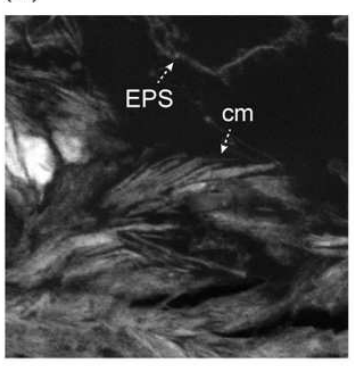

$\overline{0.4 \mu \mathrm{m}}$ (e)

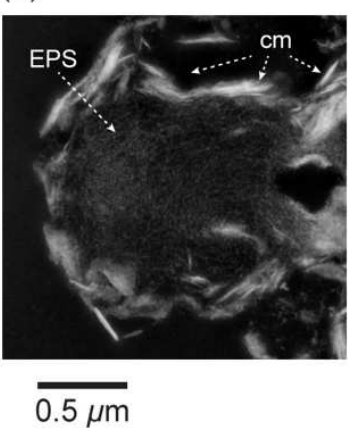

826 Supplementary Fig. S6. Selected STEM images illustrating the materials and

827 structures commonly observed within flocs FS1 and FS2. Regions of high and low

828 (clay) particle occupation are shown in (a) and (b) respectively. Note that regions of

829 high occupation primarily consisted of clay minerals aligned face-to-face, whereas

830 low occupation regions contained a variety of materials (e.g., clays, decaying organic

831 detritus, bacteria etc.). The high grey-scale values (c. $>70$ ) exhibited by units of high

832 occupation likely relates to clays coated in organic material in the nanometre range

833 filling the pore space between clay minerals. Regions of lower occupation were

834 commonly observed to consist of sub-units composed of clay platelets aligned face-

835 to-face and/or edge to face (c-d) and clay minerals arranged around a central

836 bacteria (see Fig. 5a). EPS can be observed filling the $\mathrm{nm}$ and $\mu \mathrm{m}$ pores within the

837 floc matrix (e). 
(a)

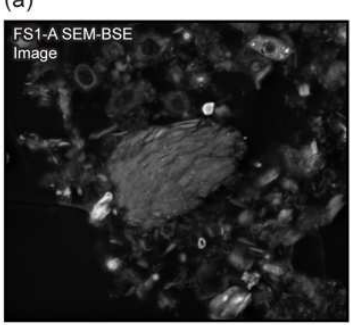

$\overline{5 \mu \mathrm{m}}$

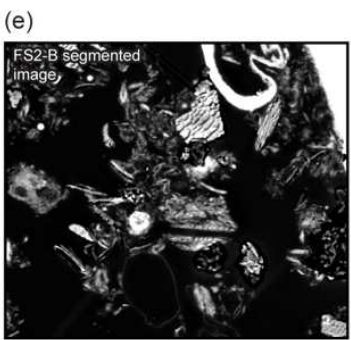

$\overline{5 \mu \mathrm{m}}$ (b)

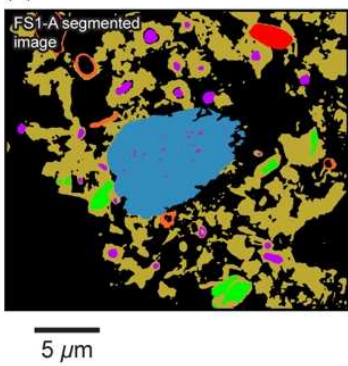

(f)

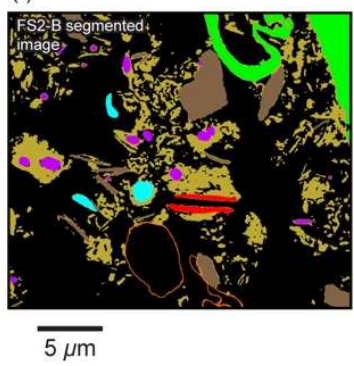

(c)

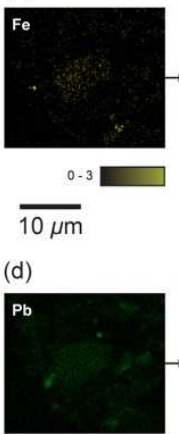

$0.5 \square \quad 0.5 \square$

$\overline{10 \mu \mathrm{m}}$
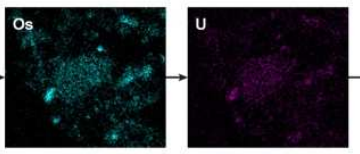

0.4

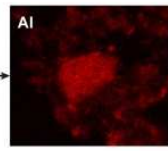

0.5

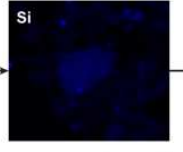

$0.5 \square$

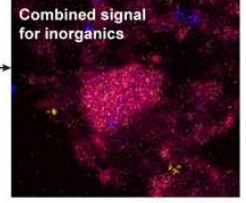

$10 \mu \mathrm{m}$

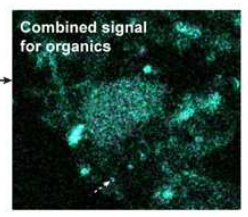

$\overline{10 \mu \mathrm{m}}$

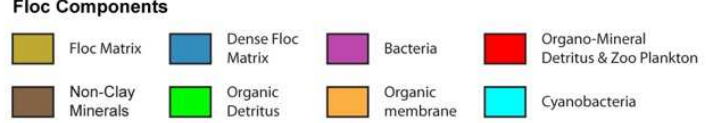

Figure 4. Characterisation of floc sub-micrometre composition and structure in 2D within Rol FS1-A

(a) and FS2-B (e). Based on features shape, grey-scale and elemental signature (c and d) the components within the Rol can be segmented ( $b$ and $f)$. The locations of Rols FS1-A and FS2-B are shown in Fig. 3c and Fig. S3 of Supplementary Materials respectively. 
Characterising the composition and multiscale structure of suspended sediment aggregates using 2D and 3D correlative microscopy

Highlights:

- Imaging workflow developed enabling multiscale floc properties to be explored for first time

- Correlative imaging enables visualisation and quantification of floc composition and structure

- Range of scale-dependent interactions observed that highlight the non-fractal nature of flocs 


\section{Declaration of interests}

$\bigotimes$ The authors declare that they have no known competing financial interests or personal relationships that could have appeared to influence the work reported in this paper.

$\square$ The authors declare the following financial interests/personal relationships which may be considered as potential competing interests:

The authors declare that they have no competing interests that may have affected the work presented in this paper. 